NASA CR-817

\section{HEAT AND MASS TRANSFER}

\section{AT A GENERAL THREE-DIMENSIONAL STAGNATION POINT}

By Paul A. Libby

Distribution of this report is provided in the interest of information exchange. Responsibility for the contents resides in the author or organization that prepared it.

Prepared under Grant No. NGR-05-009-025 by UNIVERSITY OF CALIFORNIA, SAN DIEGO

La Jolla, Calif.

for

NATIONAL AERONAUTICS AND SPACE ADMINISTRATION

For sole by the Clearinghouse for Federal Scientific and Technical Information Springfield, Virginia 22151 - CFSTI price $\$ 3.00$ 


\title{
HEAT AND MASS TRANSFER
}

\section{AT A GENERAL THREE-DIMENSIONAL STAGNATION POINT}

\author{
Paul A. Libby ${ }^{*}$ \\ University of California, San Diego \\ La Jolla, California
}

The characteristics of the boundary layer at a stagnation point with arbitrary velocity gradients in two orthogonal directions are determined. The principal parameters which characterize these layers are the ratio of velocity gradients, $c \equiv\left(d v_{\mathrm{e}} / \mathrm{dy}\right)_{0} /\left(\mathrm{du} \mathrm{e}_{\mathrm{e}} / \mathrm{dx}\right)_{0} ;$ the wall-to-stagnation temper ature ratio, $\mathrm{g}_{\mathrm{w}}$; and the mass transfer rate related to $\mathrm{f}_{\mathrm{w}}$. Solutions are obtained for a range of these parameters of interest, in particular for - $1 \leq c \leq 1$; the problem of the two-point boundary conditions is overcome by quasilinearization and exploitation of the asymptotic solutions applicable as $\eta \rightarrow \infty$. The results of applied interest relate to the heat transfer; the effect of mass transfer on the heat transfer for arbitrary $c$ is referred to the heat transfer with $c=1$, i.e., to the axisymmetric case. The heat transfer is shown to have a minimum for $c=-0.5$. Of fundamental interest are the complex, cross-flow velocity profiles, i.e., $\varphi^{\prime}$ profiles, which exhibit both reverse flow and velocity overshoot, and the existence of boundary layers with inner layer solutions of constant shear and zero-heat transfer for the saddle-point stagnation point case of $c=-1$.

This study was carried out as part of a research program being performed under NASA Grant NGR-05-009-025. The author is pleased to acknowledge the assistance of $\mathrm{Karl} \mathrm{K}$. Chen in checking the analysis, the capable programming of the numerical analysis of Judith Hays of the UCSD Computer Center, and the helpful comments of Eli Reshotko concerning this problem.

* Professor of Aerospace Engineering, Department of the Aerospace and Mechanical Engineering Sciences. Member ALAA. 


\section{Nomenclature}

\section{$A_{1}, \ldots B_{1}, \ldots C_{1}$ \\ integration constants}

a

b

C

c

$\mathbf{F}$

f

G

g

$\mathrm{H}$

h

$q_{w}$

R

$\mathrm{u}, \mathrm{v}, \mathrm{w}$

$\alpha, \beta$

$\Delta *$

$\Delta_{\mathrm{x}}, \Delta_{\mathrm{y}}$

$6^{*}$

$\eta$

$n_{1}$

$\theta_{\mathrm{x}}, \theta_{\mathrm{y}}$

$\lambda_{1,2,3}$

$\mu$ respectively

integral thicknesses

viscosity coefficient velocity gradient in the $x$-direction, $\left(d u_{e} / d x\right) x, y=0$

velocity gradient in the $y$-direction, $\left(d v_{e} / d y\right)_{x, y=0}$

ratio of mass density and viscosity coefficient, $\rho \mu / \rho_{\mathrm{e}} \mu_{\mathrm{e}}$

ratio of velocity gradients, b/a

velocity function, cf. Eq. (15)

modified stream function, cf. Eq. (6)

shear function, cf. Eq. (15)

static enthalpy ratio, $h / h$ e

shear function, cf. Eq. (15)

static enthalpy per unit mass

heat transfer rate at the surface

heat flux function, cf. Eq. (15)

velocity components in the $x, y, z$ directions,

constants in asymptotic representation of the stream

functions, cf. Eq. (17)

integral thickness, cf. Eq. (30)

displacement thickness, cf. Eq. (30)

similarity variable, cf. Eq. (6)

transformed similarity variable, cf. Eq. (18)

momentum thicknesses

factors in arguments of the exponential function 
$\sigma$

$\varphi$

\section{Subscripts}

e

w

1 velocity function, cf. Eq. (15)

mass density

Prandtl number

modified stream function, cf. Eq. (6)

conditions in the external inviscid flow
conditions at the surface, $z \sim \eta=0$
conditions for the asymptotic solution as $\eta \rightarrow \infty$,
cf. Eqs. (17) and (29).

I. Introduction

The simultaneous effects of heat and mass transfer at stagnation points, both two-dimensional and axisymmetric, have been studied extensively in the past. ${ }^{1-9}$ These studies have been motivated from a theoretical point of view by the fundamental nature of the boundary layer flow at such points, by the exact applicability there of similarity solutions and by their relevance to the leading edge and nose regions of bodies in highspeed flight.

These two cases of two-dimensional and axisymmetric flow are recognized as special cases of more general stagnation point flows as shown in Figs. la and $1 \mathrm{~b}$. In the former figure the stagnation point as might exist on an ellipsoid of revolution crosswise to the undisturbed flow is shown; this is the type of three-dimensional stagnation point treated by Howarth ${ }^{10}$ for incompressible flow and by Reshotko" for the compressible, "cold-wall" case and termed a "nodal point of attachment." In this type the $u$ and $v$ velocity 
components are everywhere directed away from the stagnation point. Figure lb shows another type of stagnation point which is termed "a saddle-point of attachment" after Davey ${ }^{12}$ and which is perhaps of less applied interest. Nevertheless this second type is of theoretical interest and indeed can arise in applications, e.g., at various points on a serrated cowling of either a supersonic or a hypersonic inlet; this type involves outflow from the origin along one coordinate and at least partial inflow along the orthogonal coordinate; its existence was apparently pointed out by Howarth but the first correct solutions for the equations of incompressible flow along with a lucid description of the physical features of these stagnation points were presented by Davey. Recently Poots $^{13}$ carried out calculations for the compressible case without mass transfer and with a Prandtl number of unity.

The various cases of these general three-dimensional stagnation points are identified by a parameter denoted here (following Howarth, 10 Davey" and Poots 13 ) as " $c$ " which is defined as

$$
c \equiv\left(d v_{e} / d y\right) /\left.\left(d u_{e} / d x\right)\right|_{x, y=0}=b / a
$$

Clearly, the two-dimensional and axisymmetric cases correspond to $c=0$, 1, respectively. For nodal points of attachment $0 \leq \mathrm{c} \leq 1$, where the $\mathrm{x}-$ coordinate is without loss in generality oriented in the direction of maximum positive velocity gradient. It is perhaps instructive to consider the streamlines in the external flow in these various cases; with $u_{e}=a x$ and $v_{e}=b y$, then the streamlines in the external flow denoted as $y_{s, e}=y_{s}(x)$ are easily found to be given by $y_{s, e} \sim x^{c}$. Again the reduction to the usual cases of $c=0,1$ is clear; there is exposed by these considerations the interesting 
additional cases $0<\mathrm{c}<1,-1<\mathrm{c}<0$. The streamlines for typical examples . thereof are shown in Fig. 1. It must be expected in general that the streamlines within the boundary layer will be quite different from those in the external flow.

Davey ${ }^{12}$ has shown that for saddle points in incompressible flows $-1 \leq \mathrm{c}<0$ where the lower limit arises from the physical requirement that as $z \rightarrow \infty, w<0$; the same considerations apply in the compressible case. Davey has also demonstrated the interesting result, again for incompressible flows, that for $c<-0.4294$ part of the boundary layer involves reverse flow; i.e., for $z>z_{c}$, the v-velocity component is directed inward as is $v_{e}$, but for $0<z<z_{c}, v$ is directed away from the stagnation point. Poots ${ }^{13}$ has not examined the effect of heat transfer on the critical value of $c$ but has shown for $c=-0.5$, for heated and adiabatic surfaces, that reverse flow does occur.

In this paper the simultaneous effects of heat and mass transfer on the properties of these general stagnation point flows over the full range of the parameter c are examined. As might be expected $̈ 0 \mathrm{r}$ such an initial study only homogeneous injection is considered and the transport properties of the gas are assumed to be described with sufficient accuracy by the frequently employed approximations $\rho \mu \approx \rho_{\mathrm{e}} \mu_{\mathrm{e}}$ and constant but nonunity Prandtl number.

Poots 13 indicates that for the cases of $c<0$, the two-point nature of the boundary conditions results in "considerable difficulties." $\mathrm{He}$

The physical explanation for flow reversal resides in the "adverse" pressure gradient experienced by the flow along the $y$-axis for $c<0$. 
employed what might be termed the straightforward, iterative scheme involving assumption of the requisite wall values (there are three in these problems) at $z=0$, integration in the direction of increasing $z$, and successive correction of the eigenvalues so that the conditions at $z \rightarrow \infty$ are satisfied. The cited difficulties might be expected by analogy with previous experience for flows with incipient separation and nonunique solutions. Since either additional or at least the same difficulties could be expected in the present study due to the effect of injection, particular attention was devoted to methods for overcoming them. The decision was made to employ the quasilinearization technique of Bellman ${ }^{14}$ and Kalaba; ${ }^{15}$ this has been applied to boundary layer problems by Radbill ${ }^{16}$ and later by Libby and Chen 17 to cases with nonunique solutions. As will be found below this decision turned out to be a proper one.

The appropriate equations for the present study have been given previously. However, to introduce the notation used here, their development and appropriate boundary conditions are outlined first; the treatrnent of the two-point boundary conditions is given next; finally the results of the numerical analysis and their significance are presented and discussed.

\section{Analysis}

In the neighborhood of a stagnation point such as those shown in Fig. 1 the boundary layer equations in Cartesian coordinates with axes aligned with the planes of symmetry are (cf. Refs. 10-13):

$$
\rho\left(\mathrm{u} \frac{\partial \mathrm{u}}{\partial \mathrm{x}}+\mathrm{v} \frac{\partial \mathrm{u}}{\partial \mathrm{y}}+\mathrm{w} \frac{\partial \mathrm{u}}{\partial x^{\mu}}\right)=\rho_{\mathrm{e}} \mathrm{x}\left(\frac{\mathrm{du} \mathrm{e}}{\mathrm{dx}}\right)^{2}+\frac{\partial}{\partial z}\left(\mu \frac{\partial \mathrm{u}}{\partial z}\right)
$$




$$
\begin{aligned}
& \rho\left(u \frac{\partial v}{\partial x}+v \frac{\partial v}{\partial y}+w \frac{\partial v}{\partial z}\right)=\rho_{e} y\left(\frac{d v e}{d y}\right)^{2}+\frac{\partial}{\partial z}\left(\mu \frac{\partial v}{\partial z}\right) \\
& \frac{\partial}{\partial x}(\rho u)+\frac{\partial}{\partial y}(\rho v)+\frac{\partial}{\partial z}(\rho w)=0 \\
& \rho\left(u \frac{\partial h}{\partial x}+v \frac{\partial h}{\partial y}+w \frac{\partial h}{\partial z}\right)=\frac{\partial}{\partial z}\left(\frac{\mu}{\sigma} \frac{\partial h}{\partial z}\right) .
\end{aligned}
$$

This system of equations is completed by an equation of state.

The boundary conditions of interest in the present context are:

At $z=0$

$$
\mathrm{u}=\mathrm{v}=0, \mathrm{w}=\mathrm{w}_{\mathrm{w}}, \mathrm{h}=\mathrm{h}_{\mathrm{w}}
$$

At $\mathbf{z} \rightarrow \infty$,

$$
u=u_{e}=\left(d u_{e} / d x\right) x=a x, \quad v=v_{e}=\left(d v_{e} / d y\right) y-b y, \quad \rho=\rho_{e}, \quad h=h_{e}
$$

where $w_{w}, h_{w}, a, b, \rho_{e}$ and $h_{e}$ are given parameters of the problem. Equations in Similarity Form

Consider now a similarity solution of the form

$$
\begin{aligned}
& \rho=\rho(\eta) \\
& \mathrm{u}=\operatorname{ax} f^{\prime}(\eta) \\
& \mathrm{v}=\operatorname{by} \varphi^{\prime}(\eta) \\
& \mathrm{h}=\mathrm{h}_{\mathrm{e}} \mathrm{g}(\eta)
\end{aligned}
$$

where the similarity variable $\eta \equiv\left(\rho_{\mathrm{e}} \mathrm{a} / \mu_{\mathrm{e}}\right)^{1 / 2} \int_{0}^{\mathrm{z}}\left(\rho / \rho_{\mathrm{e}}\right) \mathrm{dz} \mathrm{z}^{\prime}=\eta(\mathrm{z})$. Thus 
$\partial \eta / \partial \mathrm{x}=\partial \eta / \partial \mathrm{y}=0, \partial \eta / \partial \mathrm{z}=\left(\rho_{\mathrm{e}} \mathrm{a} / \mu_{\mathrm{e}}\right)^{1 / 2}\left(\rho / \rho_{\mathrm{e}}\right) ;$ moreov $; \mathrm{r}$, the continuity equation [Eq. (3)] upon substitution of Eqs. (6) and integration leads to

$$
w=-\left(\rho_{e} / \rho\right)\left(\mu_{e} a / \rho_{e}\right)^{1 / 2}(f+c \varphi)+\text { constant }
$$

where $c \equiv(b / a)$ is, as mentioned above, a crucial parameter. The constant in Eq. (7) arises from the integration. Now it will be found that in the final differential equations the finite forms of the dependent variables $f$ and $\varphi$ will appear only in the combination $(f+c \varphi)$; thus with no loss in generality the constant in Eq. (7) can be set equal to zero and the values of $f$ and $\varphi$ at $\eta=0$ can be selected conveniently as

$$
f(0) \equiv f_{w}=-(\rho w)_{w}\left(\rho_{e} \mu_{e}\right)^{-1 / 2} ; \varphi(0)=0 .
$$

Thus $f_{w}$ becomes the parameter providing the measure of the rate of mass transfer.

Substitution of Eqs. (6) and (7) into Eqs. (1), (2) and (4) leads to the following equations in similarity form;

$$
\begin{aligned}
& \left(C f^{\prime \prime}\right)^{\prime}+(f+c \varphi) f^{\prime \prime}+\left[\left(\rho_{e} / \rho\right)-f^{\prime 2}\right]=0 \\
& \left(C \varphi^{\prime \prime}\right)^{\prime}+(f+c \varphi) \varphi^{\prime \prime}+c\left[\left(\rho e_{e} / \rho\right)-\varphi^{\prime 2}\right]=0 \\
& {\left[(C / \sigma) g^{\prime}\right]^{\prime}+(f+c \varphi) g^{\prime}=0}
\end{aligned}
$$

where ()$^{\prime} \equiv d / d \eta$ and where $C \equiv\left(\rho \mu / \rho_{e} \mu_{e}\right)$ is the usual ratio of mass density 
and viscosity coefficient. For present purposes, i.e., for studying the effects of heat and mass transfer at general three-dimensional stagnation points, it is considered satisfactory to take $C \simeq 1$ and $\sigma$ constant and io assume the approximate equation of state $p \sim h^{-1}$; thus the final equations are

$$
\begin{aligned}
& f^{\prime \prime \prime}+(f+c \varphi) f^{\prime \prime}+\left(g-f^{\prime 2}\right)=0 \\
& \varphi^{\prime \prime \prime}+(f+c \varphi) \varphi^{\prime \prime}+c\left(g-\varphi^{\prime 2}\right)=0 \\
& g^{\prime \prime}+\sigma(f+c \varphi) g^{\prime}=0
\end{aligned}
$$

which are now subject to the bdundary conditions: At $\eta=0$,

$$
\mathrm{f}=\mathrm{f}_{\mathrm{w}}, \quad \varphi=\varphi^{\prime}=\mathrm{f}^{\prime}=0, \quad \mathrm{~g}=\mathrm{g}_{\mathrm{w}}
$$

At $\eta \rightarrow \infty, f^{\prime}=\varphi^{\prime}=g=1$. Examination of the boundary conditions indicates that the surface values $f_{w}{ }^{\prime \prime}, \varphi_{w} "$ and $g_{w}$ ' represent the eigenvalues in the numerical solution of Eqs. (12) to (14). Consider special cases: If $c=0$. Eqs. (12) and (14) reduce directly to those for a two-dimensional stagnatio, point as required; Eq. (13) is inessential since $\varphi$ is uninteresting in this case. If $\mathrm{c}=1$, it is necessary to let $\mathrm{f}=\left(2^{1 / 2} \tilde{\mathrm{f}}+\mathrm{f}_{\mathrm{w}}\right) / 2$ and $\eta=\widetilde{\eta} 2^{-1 / 2}$ to recover the usual equations for the axisymmetric stagnation point in terms of $\widetilde{f}$ and $g$ with $\tilde{\eta}$ as the dependent variable; in this case $\varphi \equiv f-f_{w}$ so again Eq. (13) is inessential. Finally, if $g \equiv 1$ these equations correspond to incompressible flow and have been treated by Howarth ${ }^{10}$ and Davey. 12 Nofe briefly that the four parameters identifying a solution are now: $c, \sigma$, $\mathbf{f}_{\mathbf{w}}$, and $\mathbf{g}_{\mathbf{w}}$. 
For convenience in numerical analysis, not only in integration but in application of the quasilinearization method, convert Eqs. (11) to (14) to first-order equations; introduce the new dependent variables

$$
G \equiv f^{\prime \prime}, \quad \xi=f^{\prime}, \quad H=\varphi^{\prime \prime}, \quad F=\varphi^{\prime}, \quad R=g^{\prime}
$$

so that

$$
\begin{aligned}
G^{\prime} & =-(f+c \varphi) G-\left(g-\xi^{2}\right) \\
\xi^{\prime} & =G \\
f^{\prime} & =\xi \\
H^{\prime} & =-(f+c \varphi) H-c\left(g-F^{2}\right) \\
F^{\prime} & =H \\
\varphi^{\prime} & =F \\
R^{\prime} & =-\sigma(f+c \varphi) R \\
g^{\prime} & =R
\end{aligned}
$$

subject to the boundary conditions: At $\eta=0$,

$$
\xi=F=\varphi=0 ; \quad f=f_{w} ; \quad g=g_{w}
$$

and at $\eta \rightarrow \infty$

$$
\xi=F=g=1 .
$$

In this system the eigenvalues become $G(0), H(0)$ and $R(0)$.

The Asymptotic Solutions and Uniqueness, $c>-1$

It is essential for the proper treatment of the two-point boundary conditions, at least for the case of $c<0$, to obtain the asymptotic behavior 
as $\eta \rightarrow \infty$ of $f, g$, and $\varphi$. Davey ${ }^{12}$ has shown for $c<0$ and for incompressible flow that it is not sufficient to require the conditions at $\eta \rightarrow \infty$ given above but that it is necessary to require further $\varphi^{\prime}$ to approach unity exponentially as $\eta \rightarrow \infty$. Analogous auxiliary requirements are known to be needed to assure uniqueness in a variety of boundary layer problems; from the point of view of numerical analysis their neglect can lead to difficulties of convergence in treating the two-point boundary conditions. It is to be expected that a similar requirement must be asserted in the compressible case.*

Fortunately, the requisite asymptotic solutions can be readily developed from a combination of the solutions for incompressible flow provided by Davey ${ }^{12}$ and for compressible flows at conventional stagnation points provided, e.g., in Ref. 18 .

After the usual procedure for developing asymptotic solutions, consider the special behavior of Eqs. (12) to (14) in the neighborhood of a solution as $\eta \rightarrow \infty$; accordingly, let

$$
\begin{aligned}
& f=(\eta-\alpha)+f_{1}(\eta) \\
& \varphi=(\eta-\beta)+\varphi_{1}(\eta) \\
& g=1+g_{1}(\eta)
\end{aligned}
$$

where $f_{1}, \varphi_{1}, g_{1}$ are perturbation functions and where $\alpha$ and $\beta$ are constants, whose values are inessential for present considerations. Now it will

*It is perhaps suggested that the difficulties implied by Poots ${ }^{13}$ for $c<0$ were related to improper treatment of the "infinity" conditions since he does not comment on the asymptotic behavior. 
be convenient to follow Davey ${ }^{12}$ and to treat separately the cases of $c>-1$, $c=-1 ;$ thus introduce the independent variable

$$
\eta_{1}=[\eta(1+c)-(\alpha+c \beta)](1+c)^{-1 / 2}
$$

where it is assumed that $c>-1$. Thus Eqs. (12) to (14) yield

$$
\begin{aligned}
& \frac{\mathrm{d}^{3} \mathrm{f}_{1}}{\mathrm{~d} \eta_{1}^{3}}+\eta_{1} \frac{\mathrm{d}^{2} \mathrm{f}_{1}}{\mathrm{~d} \eta_{1}^{2}}-\left(\frac{2}{1+\mathrm{c}}\right) \frac{\mathrm{df}}{\mathrm{d} \eta_{1}}=-\frac{\mathrm{g}_{1}}{(1+\mathrm{c})^{3 / 2}} \\
& \frac{\mathrm{d}^{3} \varphi_{1}}{\mathrm{~d} \eta_{1}^{3}}+\eta_{1} \frac{\mathrm{d}^{2} \varphi_{1}}{\mathrm{~d} \eta_{1}^{2}}-\left(\frac{2 \mathrm{c}}{1+\mathrm{c}}\right) \frac{\mathrm{d} \varphi_{1}}{\mathrm{~d} \eta_{1}}=-\frac{\mathrm{c} \mathrm{g}_{1}}{(1+\mathrm{c})^{3 / 2}} \\
& \frac{\mathrm{d}^{2} \mathrm{~g}_{1}}{\mathrm{~d} \eta_{1}^{2}}+\sigma \eta_{1} \frac{\mathrm{dg}{ }_{1}}{\mathrm{~d} \eta_{1}}=0 .
\end{aligned}
$$

There is only one solution to Eq. (21) permitting $g_{1} \rightarrow 0$ as $\eta_{1} \rightarrow \infty ;$ it is

$$
g_{1}=-C_{1} \int_{\eta_{1}}^{\infty} e^{-\sigma \eta^{\prime 2} / 2} d \eta^{\prime}
$$

where $C_{1}$ is an arbitrary constant; for $(\sigma / 2)^{1 / 2} \eta_{1} \gg 1$ the integral may be approximated so as to obtain the convenient form,

$$
g_{1} \simeq-\left(c_{1} / \sigma \eta_{1}\right) e^{-\sigma \eta_{1}^{2} / 2}\left[1-\left(\sigma^{-1} \eta_{1}^{-2}\right)+\ldots .\right]
$$


With this solution for $g_{1}$ Eqs. (19) and (20) may be solved for $\mathrm{df}{ }_{1} / \mathrm{d} \eta_{1}$ and $\mathrm{d} \varphi_{1} / \mathrm{d} \eta_{1}$. Davey ${ }^{12}$ has supplied the necessary complementary solutions* and the particular solutions are readily obtained by assuming solutions proportional to $n_{1}^{m} \exp \left[-\sigma \eta_{1}^{2} / 2\right]$ where $m$ is determined by substitution into the appropriate equation, i. e., either Eq. (19) or Eq. (20); thus for $\sigma \neq 1$

$$
\begin{aligned}
& \frac{\mathrm{df}}{\mathrm{d} \eta_{1}}=\mathrm{A}_{1} \eta_{1}^{-\left[2(1+\mathrm{c})^{-1}+1\right]} \mathrm{e}^{-\eta_{1}^{2} / 2}\left[1-(3+\mathrm{c})(2+\mathrm{c})(1+\mathrm{c})^{-2} \eta_{1}{ }^{-2}+\ldots\right] \\
& +B_{1} n_{1}^{2(1+c)^{-1}}\left[1+(1-c)(1+c)^{-2} n_{1}^{-2}+\ldots\right] \\
& +\left(C_{1} / \sigma^{2} \eta_{1}^{3}\right)(\sigma-1)^{-1}(1+c)^{-3 / 2} e^{-\sigma \eta_{1}^{2} / 2}[[1+[7 \sigma(1+c) \\
& \left.\left.\left.+(\sigma-1)^{2} \sigma(1+c)-(1+3 c)\right] \sigma^{-1}(\sigma-1)^{-1}(1+c)^{-1} \eta_{1}^{-2}+\ldots\right]\right]
\end{aligned}
$$

* There is a typographical error of a missing negative sign in the preexponential factors in Eqs. (4.5) and (4.6) of Ref. 12. These solutions may be found by letting $\mathrm{df} \mathrm{f}_{1} / \mathrm{d} \eta_{1}=\exp \left(-\eta_{1}{ }^{2} / 4\right) \mathrm{z}\left(\eta_{1}\right)$; there results a homogeneous Weber equation

$$
\mathrm{d}^{2} \mathrm{z} / \mathrm{d} \eta_{1}^{2}+\left[(\gamma+1 / 2)-\left(\eta_{1}^{2} / 4\right)\right] \mathrm{z}=0
$$

The asymptotic approximations thereto lead to the complementary solutions in Eqs. (24) and (25). 


$$
\begin{aligned}
& \frac{\mathrm{d} \varphi_{1}}{\mathrm{~d} \eta_{1}}=\mathrm{A}_{2} \eta_{1}^{-\left[2 \mathrm{c}(1+\mathrm{c})^{-1}+1\right]} \mathrm{e}^{-\eta_{1}^{2} / 2}\left[1-(1+3 \mathrm{c})(1+2 \mathrm{c})(1+\mathrm{c})^{-2} \eta_{1}^{-2}+\ldots\right] \\
& +\mathrm{B}_{2} \eta_{1}^{2 \mathrm{c}(1+\mathrm{c})^{-1}}\left[1-\mathrm{c}(1-\mathrm{c})(1+\mathrm{c})^{-2} \eta_{1}^{-2}+\ldots\right] \\
& +\left(\mathrm{C}_{1} \mathrm{c} / \sigma^{2} n_{1}^{3}\right)(\sigma-1)^{-1}(1+\mathrm{c})^{-3 / 2} \mathrm{e}^{-\sigma n_{1}^{2} / 2}\{1+[7 \sigma(1+\mathrm{c}) \\
& \left.\left.+c(\sigma-1)^{2} \cdot \sigma(1+c)-(3+c)\right] \sigma^{-1}(\sigma-1)^{-1} \eta_{1}^{-2}+\ldots\right\}
\end{aligned}
$$

Equation (25) indicates the nonunique behavior of $\mathrm{d} \varphi_{1} / \mathrm{d} \eta_{1} \sim \mathrm{d} \varphi_{1} / \mathrm{d} \eta$ as $\eta_{1} \sim \eta \rightarrow \infty$ provided $-1<c<0$. On the contrary the solutions for $g_{1}$ and $\mathrm{df}_{1} / \mathrm{d} n_{1}$ are unique for all values of $\mathrm{c}$ of interest.

Use of the quasilinearization procedure for the treatment of the two-point boundary conditions along the lines suggested in Ref. 17 provides a convenient means for assuring that $B_{1}$ and $B_{2}$ are zero and that the second constant set a priori equal to zero in the development of Eq. (22) is indeed zero. This may be seen as follows: Assume that there is chosen an appropriate value of $n \gg 1$, which is denoted as $\eta *$, and which is considered to be the matching point between numerical solutions and the asymptotic solutions of Eqs. (23) to (25). * Now if Eq. (23) is differentiated with respect to $n_{1}$, the constant $C_{1}$ eliminated, and the variable $\eta_{1}$ replaced by its approximate value $(f+c \varphi)(1+c)^{-1 / 2}$, there results a relation which involves $\mathrm{R}, \mathrm{g}, \mathrm{f}$ and $\varphi$ and which prevails at all values of $\eta \geq \eta^{*}$ on a

\footnotetext{
${ }^{*}$ Explicit inequalities for the determination of $\eta^{* *}$ will be given below.
} 
proper asymptotic solution for $g(\eta)$, i. e., one with the second arbitrary constant in Eq. (22) equal to zero. If this relation is imposed at $\eta=\eta *$, there is obtained

$$
R *=-\sigma(f *+c \varphi *)(g *-1)\left[1+(1+c) \sigma^{-1}\left(f *+c \varphi^{*}\right)^{-2}+\ldots\right]
$$

where ()$*$ denotes a quantity evaluated at $\eta=\eta *$. Thus a numerical solution for $g(\eta), 0 \leq \eta \leq \eta *$, which satisfies Eq. (26) will have the correct asymptotic behavior and may be continued smoothly to infinity by the selection of the single constant $C_{1}$ in Eq. (23). Selection of $n^{*}$ can be made such that the second term in the [ ] quantity on the right-hand side of Eq. (26) is negligible compared to unity.

Similar arrangements are made for the treatment of the two momentum equations; in particular Eq. (24) with $B_{1}=0$ is differentiated with respect to $\eta_{1}, A_{1}$ and $C_{1}$ eliminated, the variable $\eta_{1}$ replaced by $(f+c \varphi)(1+c)^{-1 / 2}$ and the resultant relation applied at $\eta=\eta^{*}$. Thus there is obtained

$$
\begin{aligned}
G *= & -\left(f *+c \varphi^{*}\right)(\xi *-1)\left[1+(3+c)\left(f *+c \varphi^{*}\right)^{-2}+\ldots\right] \\
& -\left(f *+c \varphi^{*}\right)^{-1} \sigma^{-1}\left(g^{*}-1\right)\left\{1+O\left[\left(f *+c \varphi^{*}\right)^{-2}\right]+\ldots\right\} .
\end{aligned}
$$

Note that the second and higher terms in the \{\} quantities in Eq. (27) are inessential because with $(f *+c \varphi) \gg 1$ the second term is small compared to the first and may be computed with less accuracy. Similarly, from Eq. (25) there is obtained 


$$
\begin{aligned}
H^{*}= & -\left(f *+c \varphi^{*}\right)\left(F^{*}-1\right)\left[1+(3 c+1)\left(f *+c \varphi^{*}\right)^{-2}+\ldots\right] \\
& -c\left(f *+c \varphi^{*}\right)^{-1} \sigma^{-1}\left(g^{*}-1\right)\left\{1+O\left[\left(f *+c \varphi^{*}\right)^{-2}\right]+\ldots\right\} .
\end{aligned}
$$

Note that additional criteria for the selection of $\eta^{*}$ derive from the righthand sides of Eqs. (27) and (28).*

The Problem of $c=-1$

For completeness it is perhaps worthwhile to consider the special, limiting case of $c=-1$. Here the equations for $f_{1}^{\prime}, \varphi_{1}{ }^{\prime}, g_{1}$ are obtained by substituting Eqs. (17) into Eqs. (12) and (14) and by linearizing; there results for $c=-1$,

$$
\begin{aligned}
& \mathrm{f}_{1}^{\prime \prime \prime}+(\beta-\alpha) \mathrm{f}_{1}^{\prime \prime}-2 \mathrm{f}_{1}^{\prime}=-\mathrm{g}_{1} \\
& \varphi_{1}^{\prime \prime \prime}+(\beta-\alpha) \varphi_{1}^{\prime \prime}+2 \varphi_{1}^{\prime}=\mathrm{g}_{1} \\
& \mathrm{~g}_{1}^{\prime \prime}+\sigma(\beta-\alpha) \mathrm{g}_{1}^{\prime}=0 .
\end{aligned}
$$

Note that for this special case as $\eta \rightarrow \infty$ the normal velocity component w becomes a negative constant, namely $-(\beta-\alpha)$, where it must be assumed on physical grounds that $\beta-\alpha>0$. This behavior is in contrast to the other cases $c>-1$ where $w \sim-\eta$ as $\eta \rightarrow \infty$ as is customary in stagnation point solutions.

Equations (29) are identical to those of Davey ${ }^{12}$ for this case provided $\mathrm{g}_{1} \equiv 0$. Davey showed numerically that $(\beta-\alpha) \simeq 2 \sqrt{2}$ "to $5 \mathrm{dec}-$ imals"; with this value assumed to be exact, he concluded by invoking the

*Note that Eqs. (27) and (28) apply for $\sigma=1$ as well as for $\sigma \neq 1$; the higher order terms in the series multiplying $\left(g^{* *}-1\right)$ are different for the two cases. 
principle of "fastest approach" that again for this case uniqueness of the solutions for $\varphi$ can only be assured if the arbitrary constant corresponding to $\mathrm{B}_{2}$ in $\mathrm{Eq}$. (25) is set equal to zero. This conclusion appears somewhat arbitrary since the solution multiplying $B_{2}$ is proportional to $\eta \exp \left(-2^{1 / 2} n\right)$ which has an acceptable, i. e., exponential, decay rather than the "forbidden" power law decay.

There appears to be no reason to assume a priori that $\beta-\alpha=2 \sqrt{2}$ but rather only that $\beta-\alpha>0$. Then solutions involving exponential decay to the last and first of Eqs. (29) can be found; thus for these, statements analogous to Eqs. (26) and (27) can be derived. However, for the second equation the characteristic equation yields complex or real values depending on the value of $\beta-\alpha$ compared to $2 \sqrt{2}$; for the cases of $\beta-\alpha \leq 2 \sqrt{2}$ there arise uniqueness questions which apparently have only somewhat arbitrary answers. Accordingly for the case of $c=-1$ an imprecise specification of infinity conditions is made with the expectation that the resulting solutions are closely representative of the flow corresponding to that value of $c$; what is specified is that $\xi^{*}=F^{*}=g^{*}=1$. Wall Solutions for Large Rates of Injection

In Refs. 9 and 19 it is shown that for large rates of injection at an axisymmetric stagnation point the boundary layer may be considered to consist of two parts; an inner layer of essentially constant shear, temperature and composition and an outer layer in which the flow properties adjust to their requisite, external values. The cases of large rates of injection are of interest in several applications wherein the rates of mass

*This "imprecise" treatment is what is usually done in boundary layer calculations. 
and convective heat transfer are effectively uncoupled; e.g., this is the case when intense radiative heat transfer occurs. However, in Ref. 20 Zeiberg has recently considered the usual similarity equations with the pressure gradient parameter $\beta$ and has shown that only for the axisymmetric case $\beta=1 / 2$ does an inner layer solution exist. The following question therefore arises: Do inner layer solutions exist for $c \neq 1$ ? To answer this question let

$$
\begin{aligned}
& \mathrm{G} \simeq \mathrm{G}_{\mathrm{w}} \\
& \xi \simeq \mathrm{G}_{\mathrm{w}} \eta \\
& \mathrm{f} \simeq \mathrm{f}_{\mathrm{w}}+\mathrm{G}_{\mathrm{w}} \eta^{2 / 2} \\
& \mathrm{H} \simeq \mathrm{H}_{\mathrm{w}} \\
& \mathrm{F} \simeq \mathrm{H}_{\mathrm{w}} \eta \\
& \varphi \simeq \mathrm{H}_{\mathrm{w}} \eta^{2} / 2 \\
& \mathrm{R} \simeq 0 \\
& \mathrm{~g} \simeq \mathrm{g}_{\mathrm{w}} .
\end{aligned}
$$

Then substitution into Eqs. (16) leads to

$$
\begin{aligned}
& G_{w}=g_{w} /\left(-f_{w}\right)=c H_{w} \\
& H_{w}=c g_{w} /\left(-f_{w}\right)=G_{w} / c
\end{aligned}
$$

which are self-consistent if $c= \pm 1$; thus in addition to the axisymmetric 
case the saddle-point solution with $c=-1$ leads to an inner solution but for no other value of $c$ do such solutions exist; this is a new result. * Quantities of Technical Interest

The result from the analysis of boundary layers at stagnation points of most technical interest is the heat transfer. Of particular concern in the present study is the variation of the heat transfer from its common two-dimensional or axisymmetric value for the same surface and mass transfer conditions. To expose this variation in a useful way there is considered the ratio $\left(\mathrm{q}_{\mathrm{w}} / \mathrm{q}_{\mathrm{w}, 1}\right)$ with $\sigma, \mathrm{f}_{\mathrm{w}}$ and $\mathrm{g}_{\mathrm{w}}$ fixed as a function of the parameter $c$, where $q_{w, l}$ is the heat transfer to the axisymmetric stagnation point $(c=1)$ and $q_{w}$ is the heat transfer for generic $c$.

With the assumptions employed here relative to the transport properties of the gas it is found that

$$
\frac{q_{w}}{q_{w, 1}}=\frac{R\left(0 ; c, \sigma, f_{w}, g_{w}\right)}{R\left(0 ; 1, \sigma, f_{w}, g_{w}\right)}
$$

where the parameters influencing this ratio of heat transfers are emphasized.

Other quantities of technical interest from stagnation point solutions are measures of the boundary layer thicknesses which may be specified in terms of "edge" values of $\eta$; more convenient are integral specifications. Momentum thicknesses in both the $x$ and $y$ directions may be defined as

$$
\begin{aligned}
& \theta_{\mathrm{x}} \equiv \int_{0}^{\infty}\left(\rho \mathrm{u} / \rho_{\mathrm{e}} \mathrm{u}_{\mathrm{e}}\right)\left[\mathrm{l}-\left(\mathrm{u} / \mathrm{u}_{\mathrm{e}}\right)\right] \mathrm{dz} \\
& \theta_{\mathrm{y}} \equiv \int_{0}^{\infty}\left(\rho \mathrm{v} / \rho_{\mathrm{e}} \mathrm{v}_{\mathrm{e}}\right)\left[1-\left(\mathrm{v} / \mathrm{v}_{\mathrm{e}}\right)\right] \mathrm{d} \mathrm{z} .
\end{aligned}
$$

* The author is indebted to S. L. Zeiberg for a useful exchange concerning this result. 
These lead to the convenient forms

$$
\begin{aligned}
& \left(\rho_{\mathrm{e}}{ }^{\mathrm{a} / \mu_{\mathrm{e}}}\right)^{1 / 2} \theta_{\mathrm{x}}=\Delta_{\mathrm{x}} \equiv \int_{0}^{\infty} f^{\prime}\left(1-f^{\prime}\right) \mathrm{d} \eta \\
& \left(\rho_{\mathrm{e}}{ }^{\mathrm{a} / \mu_{\mathrm{e}}}\right)^{1 / 2} \theta_{\mathrm{x}}=\Delta_{\mathrm{y}} \equiv \int_{0}^{\infty} \varphi^{\prime}\left(1-\varphi^{\prime}\right) \mathrm{d} \eta .
\end{aligned}
$$

The displacement thickness in this three-dimensional case must be defined after Moore ${ }^{21}$ and Lighthill ${ }^{22}$ extended to include mass transfer as

$$
-(\rho \mathrm{w})_{\mathrm{w}}+\frac{\mathrm{d}}{\mathrm{dx}}\left[\rho_{\mathrm{e}} \mathrm{u}^{\delta *}-\int_{0}^{\infty}\left(\rho_{\mathrm{e}} \mathrm{u}_{\mathrm{e}}-\rho \mathrm{u}\right) \mathrm{dz}\right]+\frac{\mathrm{d}}{\mathrm{dy}}\left[\rho_{\mathrm{e}} \mathrm{v}^{\delta *}-\int_{0}^{\infty}\left(\rho_{\mathrm{e}} \mathrm{e}^{-\rho \mathrm{v}}\right) \mathrm{dz}\right]=0
$$

which leads to the convenient form

$$
\begin{aligned}
\left(\rho_{\mathrm{e}}^{\mathrm{a} / \mu_{\mathrm{e}}}\right)^{1 / 2} \delta * & =\int_{0}^{\infty}\left[g-\left(f^{\prime}+c \varphi^{\prime}\right)(1+\mathrm{c})^{-1}\right] \mathrm{d} \eta-\left[f_{\mathrm{w}} /(1+\mathrm{c})\right] \\
& =\Delta *-\left[f_{\mathrm{w}} /(1+\mathrm{c})\right] .
\end{aligned}
$$

It is perhaps worth noting that there has been some recent discussion (cf. Refs. 23 and 24) of the proper definition of displacement thickness for boundary layers with mass transfer. Here the view is taken that the suitable definition depends on the use to which the quantity is to be put and that following Moore and Lighthill the distance the wall must be displaced to alter an entirely inviscid flow the same amount as the boundary layer does is one definition; indeed $\delta *$ given here is just this distance. *

To be precise the distribution of the $z$-velocity component in the inviscid flow is $-w_{e}=a(1+c)(z-\delta *)$ according to the definition of $\delta * \mathrm{em}$ ployed here. 


\section{The Numerical Analysis}

The quasilinear version of Eqs. (16) involves iteration indices $k$ and $(k+1)$ on each dependent variable and is ${ }^{*}$ (cf. Refs. 14-17)

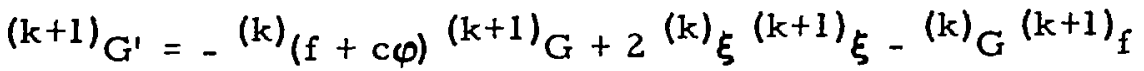

$$
\begin{aligned}
& -c^{(k)} G(k+1) \varphi-{ }^{(k+1)} g+{ }^{(k)}(f+c \varphi)^{(k)} G-{ }^{(k)} \xi^{2} \\
& (k+1)_{\xi^{\prime}}={ }^{(k+1)} G \\
& (k+1)_{f^{\prime}}=(k+1)_{\xi} \\
& (k+1)_{H^{\prime}}=-{ }^{(k)_{H}}(k+1)_{f}-{ }^{(k)}(f+c \varphi){ }^{(k+1)_{H}+2 c^{(k)}}{ }_{F}^{(k+1)} F \\
& -c^{(k)}{ }_{H}^{(k+1)} \varphi-c^{(k+1)} g+{ }^{(k)}(f+c \varphi){ }^{(k)} H-c^{(k)} F^{2} \\
& { }^{(k+1)_{F^{\prime}}}={ }^{(k+1)} \mathrm{H} \\
& (\mathrm{k}+1)_{\varphi^{\prime}}={ }^{(\mathrm{k}+1)_{F}} \\
& { }^{(k+1)} R^{\prime}=-\sigma^{(k)_{R}}{ }^{(k+1)} f-\sigma c^{(k)_{R}}{ }^{(k+1)} \varphi-\sigma^{(k)}(f+c \varphi)^{(k+1)} R \\
& +\sigma^{(k)}(f+c \varphi)^{(k)} R \\
& (k+1)_{g^{\prime}}={ }^{(k+1)}{ }_{R} \text {. }
\end{aligned}
$$

The idea of quasilinearization is readily understood as follows: Consider the system of first-order equations

$$
\mathrm{dy}_{\mathrm{i}} / \mathrm{dx}=\mathrm{g}_{\mathrm{i}}\left(\mathrm{y}_{1}, \ldots \mathrm{y}_{\mathrm{N}}, \mathrm{x}\right), \quad \mathrm{i}=1 \ldots \mathrm{N} \text {. }
$$

The quasilinear version thereof is

$$
{ }^{(k+1)}\left(d y_{i} / d x\right)=(k) g_{i}+\sum_{j=1}^{N}(k)\left(\partial g_{i} / \partial y_{j}\right)\left((k+1) y_{j}-(k) y_{j}\right), i=1, \ldots N \text {. }
$$


Note that if all dependent variables in two successive iterations are identical, i. e., if ${ }^{(k+1)} G \equiv{ }^{(k)} G,{ }^{(k+1)} \xi \equiv{ }^{(k)} \xi$, etc., then Eqs. (33) are identical with the original set of Eqs. (16). The point of view relative to Eqs. (33) is that the functions labeled with the index. $k$ are assumed known and those with the index $(k+1)$ are to be determined. Finally, note that the last two terms on the right-hand sides of the first, fourth, and seventh equations are essentially inhomogeneous terms so that both complementary and particular solutions must be found numerically.

The numerical treatment can be carried out in a straightforward manner. Assume that there is given a set of parameters; $c, \sigma, f_{w}$, and $\mathrm{g}_{\mathrm{w}}$, and initial approximations for the functions $\mathrm{G}, \mathrm{H}$ and $\mathrm{R}$ which are denoted, respectively, as ${ }^{(0)} \mathrm{G}, \quad{ }^{(0\rangle} \mathrm{H}$ and ${ }^{(0)_{\mathrm{R}}}$ and which may be either rough guesses or may be obtained from an available solution for a "neighboring" set of parameters. Assume further that from Eqs. (26) to (28) a value of $\eta^{*}$ has been estimated. Typically, the form of Eqs. (26) to (28) employed in iteration is shown by Eq. (27), namely

$$
\begin{aligned}
& (k+1)_{G *}=-\left({ }^{(k)} f_{*}+c^{(k)} \varphi^{*}\right)\left({ }^{(k+1)} \xi_{*}-1\right)\left[1+(3+c)\left({ }^{(k)} f_{*}+c{ }^{(k)} \varphi^{*}\right)^{-2}+\ldots\right]
\end{aligned}
$$

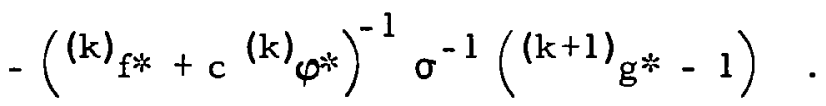

Note that this form is not strictly the one which would follow from formal application of the quasilinearization idea but is a simpler one based on the idea that the only large quantity in these boundary conditions is $\left(* f+c \varphi^{*}\right)$ and that only small percentage changes in it are likely between iterations. 
It is now possible to proceed with the method of solution:

Three complementary solutions denoted by
(1) $\mathrm{G}_{1},{ }^{(1)} \xi_{1}$,
$(1)_{f_{1}}, \ldots$
(1) $\mathrm{g}_{1}$
${ }^{(1)} \mathrm{G}_{2}$,
${ }^{(1)_{\xi_{2}}},(1)_{f_{2}}, \ldots$
${ }^{(1)} \mathrm{g}_{2}$,
${ }^{(1)} \mathrm{G}_{3}, \ldots\left({ }^{(1)} \mathrm{g}_{3}\right.$

and a particular solution denoted by ${ }^{(1)} G_{p},{ }^{(1)} \xi_{p}, \ldots$ (1) $g_{p}$ are found; these may conveniently be subject to the following conditions at $\eta=0$ : ${ }^{(1)} \mathrm{G}_{1}(0)={ }^{(1)} \mathrm{H}_{2}(0)={ }^{(1)} \mathrm{R}_{3}(0)=1, \quad(1)_{f_{\mathrm{p}}}(0)=\mathrm{f}_{\mathrm{w}}, \quad{ }^{(1)} \mathrm{g}_{\mathrm{p}}(0)=\mathrm{g}_{\mathrm{w}}$ with all other initial conditions equal to zero. These solutions are combined so that typically

$$
\begin{aligned}
& (1)_{\mathrm{G}(\eta)}={ }^{(1)} \mathrm{A}_{1}{ }^{(1)} \mathrm{G}_{1}(\eta)+{ }^{(1)} \mathrm{A}_{2}(1)_{\mathrm{G}_{2}}(\eta)+{ }^{(1)} \mathrm{A}_{3}(1) \mathrm{G}_{3}(\eta)+{ }^{(1)} \mathrm{G}_{\mathrm{p}}(\eta) \\
& (1)_{\xi}(\eta)={ }^{(1)} \mathrm{A}_{1}{ }^{(1)} \xi_{1}(\eta)+{ }^{(1)} \mathrm{A}_{2}{ }^{(1)} \xi_{2}(\eta)+{ }^{(1)} \mathrm{A}_{3}{ }^{(1)} \xi_{3}(\eta)+{ }^{(1)} \xi_{\mathrm{p}}(\eta)
\end{aligned}
$$

and similarly for the other six dependent variables. The constants (1) $A_{i}$, $i=1,2,3$ are determined from Eqs. (26) to (28), each in linear form. Thus the combined solution satisfies all boundary conditions. Note that the initial conditions for each solution have been chosen such that ${ }^{(1)} G(0)=$ ${ }^{(1)} \mathrm{A}_{1}, \quad{ }^{(1)} \mathrm{H}(0)={ }^{(1)} \mathrm{A}_{2}$, and $(1)_{\mathrm{R}(0)}={ }^{(1)} \mathrm{A}_{3}$.

Another cycle of iteration can be carried out by replacing the initial guesses ${ }^{(0)} G,{ }^{(0)} \xi$, etc., by ${ }^{(1)_{G}},{ }^{(1)} \xi, \ldots$, etc., and the cycles continued until some suitable convergence criterion is satisfied. In addition, the suitability of $\eta^{*}$ can be checked after each or after several cycles. After convergence the integrals $\Delta_{\mathrm{x}}, \Delta_{\mathrm{y}}$ and $\Delta_{*}$ of interest in applications may be computed. 


\section{Numerical Results}

In this section the solutions to the final equations discussed above are presented. Perhaps some remarks concerning the numerical analysis are in order. The solutions to the quasilinear equations were obtained by a Kutta-Runge integration procedure with a fixed step-size of 0.05 . The value of $\eta^{*}$ was taken to be in the range $8 \leq \eta^{*} \leq 16$ but determined by the condition $\left(f *+c \varphi^{*}\right)^{2} \geq 10^{2}$. The first iterate $(k=0)$ for each solution was taken to be a previously obtained solution of a neighboring problem in the sense of corresponding to "adjacent" values of $c, f_{w}$ and/or $g_{w}$. Convergence was considered to have been achieved when $f_{w} ", \varphi_{w}$ ", and $\mathrm{g}_{\mathrm{w}}{ }^{\prime}$ in two successive iterates agreed within $10^{-4}$. Experience indicated that convergence was obtained in from two to ten cycles depending on the value of $c$ and on the first iterate $(k=0)$; generally convergence was slower for $\mathrm{c}<0$. The calculations were carried out on the CDC 3600 and took less than 30 seconds per solution. For cases of $c=-1$ wherein primative conditions at "infinity" were imposed $\eta^{*}$ was taken to be 16 .

Solutions were obtained for three values of $g_{w}$, namely 0,1 and 2, for a range of $-f_{\mathrm{w}}$ from 0 to 2 , and for the range of $1 \leq \mathrm{c} \leq 1$. Several calculations for large rates of injection were made for $g_{w}=0$. 1 . The integral thicknesses were computed by Simpson's rule after convergence was achieved. Note that the case of $\mathrm{g}_{\mathrm{w}}=1$ corresponds to incompressible flow so that in Eqs. (12) and (13) and in the definition of $\Delta *$ [cf. Eq. (32)], $g \simeq 1$; nevertheless the energy equation has been solved for $g(\eta)$ to obtain the "incompressible" heat transfer by making minor modifications in the computer program.

\footnotetext{
* The difference in the wall values, integral thicknesses, etc., between $\eta^{*}=8$ or 16 was found generally to be in the third or fourth significant figure.
} 
It is remarked here that the experience obtained with quasilinearization for the present problem indicates that it is indeed a powerful technique for handling the problem of the two-point boundary condition in complex boundary layers.

The Wall Values and the Intẹgral Thicknesses

The results of the numerical solutions can be presented in several ways. In the interests of brevity Table I lists the critical wall values $f_{w}^{\prime \prime}, \varphi_{w}{ }^{\prime \prime}, g_{w}{ }^{\prime} /\left(1-g_{w}\right)$, the integral thicknesses $\Delta_{x}, \Delta_{y}$ and $\Delta *$ and the parameters $\alpha$ and $\beta, \alpha=\lim _{\eta \rightarrow \infty}(\eta-f), \beta=\lim _{\eta \rightarrow \infty}(\eta-\varphi)$. From this tabulation a variety of studies can be made and indeed with the wall values given it is a simple matter to obtain by direct integration of Eqs. (16) the various profiles, i.e., $f^{\prime}, \varphi^{\prime}$, and $g$.

The values of $f_{w}$ " and of $\varphi_{w}$ " may be compared for the incompressible case of $\mathrm{g}_{\mathrm{w}}=1$ and of zero mass transfer with the values given by Howarth ${ }^{10}$ and Davey ${ }^{12}$. Excellent agreement will be noted with Howarth but there are some relatively minor discrepancies with Davey for $c<0$, probably due to different methods of numerical analysis. There is a discrepancy with Davey relative to the value of $\beta-\alpha$ for $c=-1, f_{w}=0$, $\mathrm{g}_{\mathrm{W}}=1$; with the imprecise specification of the boundary condition at $\eta^{*}=16$ used here and with the present numerical analysis it is found that $\beta-\alpha=$ 2. 6983 and not " $2 \sqrt{2}$ to 5 decimals." It is noted that this discrepancy is not altered by increasing $\eta^{*}$ from 8 to 16 . Note further that the present results for $f_{w}=0, g_{w} \neq 1$ differ somewhat from those of Poots ${ }^{13}$ because $\sigma=0.7$ here versus $\sigma=1$ in his work. 
The Heat Transfer

Of applied interest from the present study is the influence of mass transfer on the heat transfer for various degrees of three-dimensionality, i. e., for various values of c. In Figs. 2 to 4 the ratio $\left(q_{w} / q_{w, 1}\right)$ is presented versus $c$ for various values of $-f_{w}$ and for $g_{w}=0,1,2$, respectively. Comparison of these figures indicates that mass transfer reduces the heat transfer with $c<1$ relative to that at an axisymmetric stagnation point $(c=1)$ with the same mass transfer to a much greater extent if the surface is cold, i. e., if $\mathrm{g}_{\mathrm{w}} \approx 0$. Moreover, each figure indicates that for $c=-0.5$ the heat transfer either with or without mass transfer is a minimum, i. e., the heat transfer at a stagnation point with inflow along one plane of symmetry and outflow along the second such that $c \approx-0.5$ is less than at a two-dimensional, $c=0$, stagnation point. This appears not to have been observed before.

Since Figs. 2 to 4 relate the heat transfer to its corresponding axisymmetric value it is convenient for completeness to present for $c=1$ the quotient $g_{w}{ }^{\prime} /\left(1-g_{w}\right)^{-1}$ versus $-f_{w}$ as in Fig. 5. These values are not new (cf. Ref. 3, e.g.).

In connection with Fig. 3 it is of interest to note that the large changes in boundary layer behavior associated with small changes in $c$ from unity pointed out for incompressible flow by Howarth are not reflected in the heat transfer which decreases in a rather smooth fashion in the range $-0.5 \lesssim c \lesssim 1$.

The Profiles

In the interests of brevity only the more unusual aspects of the profiles associated with the solutions obtained here will be discussed. In 
general the $\mathbf{x}$-wise velocity profiles $f^{\prime}(\eta)$ and the enthalpy profiles $g(\eta)$ are as might be expected and are therefore not presented. On the contrary the $\mathrm{y}$-wise velocity profiles exhibit considerable complexity with reverse flow and velocity overshoot occurring in one profile. In Figs. 6 to 9 the $\varphi^{\prime}$ profiles for $-f_{w}=0,1$ and for $g_{w}=0,2$ are shown; particular attention is called to the profiles for $c=-0.75$ which clearly exhibit reverse flow and overshoot. This behavior is due to the competition among inertia, pressure and shear stress effects through the thickness of the boundary layer, and incidentally leads to great difficulty in the handling of the twopoint boundary conditions by forward-integration techniques.

The other aspect of the profiles of interest concerns the cases of large injection rates wherein inner layer solutions appear; since those for $c=1$ have been demonstrated elsewhere (cf. Refs. 9, 19) attention has been confined here to $c=-1$; shown in Figs. 10 and 11 are the profiles for $f^{\prime}, \varphi^{\prime}$ and $g$ for $-f_{w}=3$, and for $g_{w}=0.1$ and 2 . Shown are the inner layer solutions for comparison purposes. Clearly these profiles are interesting. 
Table I Numerical Results

\begin{tabular}{|c|c|c|c|c|c|c|c|c|c|}
\hline c & $-f_{w}$ & $f_{w}^{\prime \prime}$ & $\varphi_{\mathrm{w}}{ }^{\prime \prime}$ & $\mathbf{g}_{w}{ }^{1 /\left(1-g_{w}\right)}$ & $\Delta_{x}$ & $\Delta_{\mathrm{y}}$ & $\Delta^{*}$ & $\alpha$ & $\boldsymbol{\beta}$ \\
\hline $\mathbf{g}_{\mathbf{w}}=0$ & & & & & - & & & & \\
\hline 1 & $\begin{array}{l}0 \\
0.25 \\
0.50 \\
0.75 \\
1.00 \\
1.25 \\
1.50\end{array}$ & $\begin{array}{l}0.7821 \\
0.6154 \\
0.4614 \\
0.3225 \\
0.2014 \\
0.1021 \\
0.0301\end{array}$ & $\begin{array}{l}0.7821 \\
0.6154 \\
0.4614 \\
0.3225 \\
0.2014 \\
0.1021 \\
0.0301\end{array}$ & $\begin{array}{l}0.6058 \\
0.4830 \\
0.3677 \\
0.2616 \\
0.1669 \\
0.0867 \\
0.0263\end{array}$ & $\begin{array}{l}0.3056 \\
0.3477 \\
0.3839 \\
0.4260 \\
0.4751 \\
0.5333 \\
0.6040\end{array}$ & $\begin{array}{l}0.3056 \\
0.3477 \\
0.3839 \\
0.4260 \\
0.4751 \\
0.5333 \\
0.6040\end{array}$ & $\begin{array}{l}-0.1483 \\
-0.1776 \\
-0.1903 \\
-0.2054 \\
-0.2239 \\
-0.2479 \\
-0.2818\end{array}$ & $\begin{array}{l}2.7842 \\
1.1476 \\
1.5432 \\
1.9873 \\
2.5115 \\
3.1908 \\
4.2914\end{array}$ & $\begin{array}{l}2.7842 \\
0.8976 \\
1.0432 \\
1.2373 \\
1.5115 \\
1.9408 \\
2.7914\end{array}$ \\
\hline 0.5 & $\begin{array}{l}0 \\
0.25 \\
0.50 \\
0.75 \\
1.00 \\
1.25\end{array}$ & $\begin{array}{l}0.6989 \\
0.5329 \\
0.3811 \\
0.2464 \\
0.1327 \\
0.0458\end{array}$ & $\begin{array}{l}0.6555 \\
0.4904 \\
0.3414 \\
0.2122 \\
0.1074 \\
0.0332\end{array}$ & $\begin{array}{l}0.5257 \\
0.4037 \\
0.2907 \\
0.1890 \\
0.1019 \\
0.0348\end{array}$ & $\begin{array}{l}0.3364 \\
0.4055 \\
0.4556 \\
0.5157 \\
0.5894 \\
0.6829\end{array}$ & $\begin{array}{l}0.3391 \\
0.4084 \\
0.4574 \\
0.5143 \\
0.5803 \\
0.6561\end{array}$ & $\begin{array}{l}-0.1581 \\
-0.2108 \\
-0.2294 \\
-0.2524 \\
-0.2822 \\
-0.3244\end{array}$ & $\begin{array}{l}0.8922 \\
1.2910 \\
1.7401 \\
2.2717 \\
2.9595 \\
4.0460\end{array}$ & $\begin{array}{l}0.9184 \\
1.0771 \\
1.2901 \\
1.5913 \\
2.0575 \\
2.9363\end{array}$ \\
\hline 0 & $\begin{array}{l}0 \\
0.25 \\
0.50 \\
0.75 \\
1.00 \\
1.25\end{array}$ & $\begin{array}{l}0.6071 \\
0.4435 \\
0.2966 \\
0.1704 \\
0.0705 \\
0.0067\end{array}$ & $\begin{array}{l}0.4970 \\
0.3354 \\
0.1984 \\
0.0931 \\
0.0263 \\
0.0008\end{array}$ & $\begin{array}{l}0.4362 \\
0.3173 \\
0.2102 \\
0.1185 \\
0.0471 \\
0.0040\end{array}$ & $\begin{array}{l}0.3680 \\
0.4984 \\
0.5725 \\
0.6642 \\
0.7802 \\
0.9208\end{array}$ & $\begin{array}{l}0.3723 \\
0.5107 \\
0.5784 \\
0.6477 \\
0.7068 \\
0.7197\end{array}$ & $\begin{array}{l}-0.1891 \\
-0.3033 \\
-0.3485 \\
-0.4080 \\
-0.4899 \\
-0.5896\end{array}$ & $\begin{array}{l}1.0560 \\
1.5145 \\
2.0567 \\
2.7496 \\
3.7824 \\
6.3947\end{array}$ & $\begin{array}{l}1.1578 \\
1.4166 \\
1.7842 \\
2.3389 \\
3.2845 \\
5.8725\end{array}$ \\
\hline-0.5 & $\begin{array}{l}0 \\
0.25 \\
0.50 \\
0.75 \\
1.00 \\
1.25\end{array}$ & $\begin{array}{l}0.4940 \\
0.3481 \\
0.2254 \\
0.1263 \\
0.0509 \\
0.0041\end{array}$ & $\begin{array}{r}0.3592 \\
0.1857 \\
0.0660 \\
0.0036 \\
-0.0116 \\
-0.0018\end{array}$ & $\begin{array}{l}0.3246 \\
0.2248 \\
0.1431 \\
0.0788 \\
0.0309 \\
0.0023\end{array}$ & $\begin{array}{l}0.3920 \\
0.6863 \\
0.7761 \\
0.8575 \\
0.9670 \\
1.0886\end{array}$ & $\begin{array}{r}0.3703 \\
0.3562 \\
0.3142 \\
0.2064 \\
0.0508 \\
-0.1159\end{array}$ & $\begin{array}{l}-0.3146 \\
-0.4379 \\
-0.6691 \\
-0.9664 \\
-1.3206 \\
-1.7284\end{array}$ & $\begin{array}{l}1.3876 \\
1.9269 \\
2.5460 \\
3.3993 \\
4.3920 \\
7.1798\end{array}$ & $\begin{array}{l}1.2243 \\
1.6266 \\
2.1611 \\
3.8955 \\
4.0097 \\
6.9873\end{array}$ \\
\hline-0.75 & $\begin{array}{l}0 \\
0.25 \\
0.50 \\
0.75 \\
1.00 \\
1.25\end{array}$ & $\begin{array}{l}0.5597 \\
0.4224 \\
0.2982 \\
0.1893 \\
0.0987 \\
0.0313\end{array}$ & $\begin{array}{r}0.0292 \\
-0.0513 \\
-0.0841 \\
-0.0810 \\
-0.0552 \\
-0.0211\end{array}$ & $\begin{array}{l}0.3854 \\
0.2929 \\
0.2082 \\
0.1331 \\
0.0697 \\
0.0220\end{array}$ & $\begin{array}{l}0.5214 \\
0.5657 \\
0.6161 \\
0.6744 \\
0.7431 \\
0.8268\end{array}$ & $\begin{array}{r}0.4498 \\
0.3531 \\
0.2232 \\
0.0684 \\
-0.1024 \\
-0.2780\end{array}$ & $\begin{array}{l}-3.5718 \\
-4.4335 \\
-5.3160 \\
-6.2114 \\
-7.1187 \\
-8.0377\end{array}$ & $\begin{array}{l}1.2055 \\
1.6289 \\
2.1060 \\
2.6723 \\
3.4097 \\
4.5989\end{array}$ & $\begin{array}{l}2.2771 \\
2.7301 \\
3.2426 \\
3.8470 \\
4.6237 \\
5.8543\end{array}$ \\
\hline & $\begin{array}{l}0 \\
0.25 \\
0.50 \\
0.75 \\
1.00 \\
1.25\end{array}$ & $\begin{array}{l}0.6631 \\
0.5139 \\
0.3774 \\
0.2556 \\
0.1514 \\
0.0684\end{array}$ & $\begin{array}{l}-0.2890 \\
-0.2716 \\
-0.2323 \\
-0.1784 \\
-0.1176 \\
-0.0583\end{array}$ & $\begin{array}{l}0.4863 \\
0.3812 \\
0.2836 \\
0.1951 \\
0.1175 \\
0.0541\end{array}$ & $\begin{array}{l}0.4057 \\
0.4417 \\
0.4828 \\
0.5298 \\
0.5842 \\
0.6484\end{array}$ & $\begin{array}{r}0.2185 \\
0.0703 \\
-0.0903 \\
-0.2599 \\
-0.4352 \\
-0.6145\end{array}$ & $\begin{array}{l}\infty \\
\infty \\
\infty \\
\infty \\
\infty \\
\infty\end{array}$ & $\begin{array}{l}0.9691 \\
1.3550 \\
1.7796 \\
2.2639 \\
2.8511 \\
3.6536\end{array}$ & $\begin{array}{l}3.6489 \\
4.0299 \\
4.4481 \\
4.9242 \\
5.4994 \\
6.2816\end{array}$ \\
\hline \multicolumn{10}{|l|}{$\mathrm{g}_{\mathbf{w}}=1$} \\
\hline I & $\begin{array}{l}0 \\
0.25 \\
0.50 \\
0.75 \\
1.00 \\
1.25\end{array}$ & $\begin{array}{l}1.3119 \\
1.1674 \\
1.0340 \\
0.9125 \\
0.8036 \\
0.7074\end{array}$ & $\begin{array}{l}1.3119 \\
1.1674 \\
1.0340 \\
0.9125 \\
0.8036 \\
0.7074\end{array}$ & $\begin{array}{l}0.6654 \\
0.5529 \\
0.4492 \\
0.3555 \\
0.2728 \\
0.2021\end{array}$ & $\begin{array}{l}0.2477 \\
0.2659 \\
0.2858 \\
0.3075 \\
0.3310 \\
0.3564\end{array}$ & $\begin{array}{l}0.2417 \\
0.2659 \\
0.2858 \\
0.3075 \\
0.3310 \\
0.3564\end{array}$ & $\begin{array}{l}0.5689 \\
0.6196 \\
0.6765 \\
0.7400 \\
0.8105 \\
0.8883\end{array}$ & $\begin{array}{l}0.5689 \\
0.8696 \\
1.1765 \\
1.4900 \\
1.8105 \\
2.1383\end{array}$ & $\begin{array}{l}0.5689 \\
0.6196 \\
0.6765 \\
0.7400 \\
0.8105 \\
0.8883\end{array}$ \\
\hline 0.5 & $\begin{array}{l}0 \\
0.25 \\
0.50 \\
0.75 \\
1.00 \\
1.25\end{array}$ & $\begin{array}{l}1.2669 \\
1.1250 \\
0.9950 \\
0.8777 \\
0.7733 \\
0.6821\end{array}$ & $\begin{array}{l}0.9981 \\
0.8522 \\
0.7206 \\
0.6047 \\
0.5052 \\
0.4224\end{array}$ & $\begin{array}{l}0.5797 \\
0.4687 . \\
0.3671 \\
0.2777 \\
0.2014 \\
0.1390\end{array}$ & $\begin{array}{l}0.2695 \\
0.2913 \\
0.3153 \\
0.3416 \\
0.3704 \\
0.4017\end{array}$ & $\begin{array}{l}0.3024 \\
0.3292 \\
0.3586 \\
0.3907 \\
0.4254 \\
0.4625\end{array}$ & $\begin{array}{l}0.6430 \\
0.7083 \\
0.7826 \\
0.8667 \\
0.9610 \\
1.0658\end{array}$ & $\begin{array}{l}0.6089 \\
0.9166 \\
1.2315 \\
1.5541 \\
1.8849 \\
2.2239\end{array}$ & $\begin{array}{l}0.7112 \\
0.7919 \\
0.8850 \\
0.9918 \\
1.1132 \\
1.2495\end{array}$ \\
\hline 0 & $\begin{array}{l}0 \\
0.25 \\
0.50 \\
0.75 \\
1.00 \\
1.25\end{array}$ & $\begin{array}{l}1.2326 \\
1.0948 \\
0.9692 \\
0.8564 \\
0.7566 \\
0.6694\end{array}$ & $\begin{array}{l}0.5705 \\
0.4216 \\
0.2950 \\
0.1931 \\
0.1168 \\
0.0644\end{array}$ & $\begin{array}{l}0.4959 \\
0.3884 \\
0.2933 \\
0.2121 \\
0.1456 \\
0.0943\end{array}$ & $\begin{array}{l}0.2923 \\
0.3170 \\
0.3441 \\
0.3737 \\
0.4058 \\
0.4403\end{array}$ & $\begin{array}{l}0.4042 \\
0.4443 \\
0.4841 \\
0.5209 \\
0.5513 \\
0.5730\end{array}$ & $\begin{array}{l}0.6479 \\
0.7107 \\
0.7810 \\
0.8590 \\
0.9450 \\
1.0388\end{array}$ & $\begin{array}{l}0.6479 \\
0.9607 \\
1.2810 \\
1.6090 \\
1.9450 \\
2.2888\end{array}$ & $\begin{array}{l}1.0262 \\
1.1931 \\
1.3940 \\
1.6320 \\
1.9076 \\
2.2180\end{array}$ \\
\hline-0.5 & $\begin{array}{l}0 \\
0.25 \\
0.50 \\
0.75 \\
1.00 \\
1.25\end{array}$ & $\begin{array}{l}1.2107 \\
1.0826 \\
0.9648 \\
0.8575 \\
0.7608 \\
0.6750\end{array}$ & $\begin{array}{r}0.3377 \\
0.0920 \\
-0.0848 \\
-0.1991 \\
-0.2618 \\
-0.2860\end{array}$ & $\begin{array}{l}0.3913 \\
0.3098 \\
0.2396 \\
0.1799 \\
0.1302 \\
0.0900\end{array}$ & $\begin{array}{l}0.3175 \\
0.3383 \\
0.3603 \\
0.3838 \\
0.4091 \\
0.4365\end{array}$ & $\begin{array}{l}-0.7567 \\
-0.7221 \\
-0.7526 \\
-0.8400 \\
-0.9734 \\
-1.1413\end{array}$ & $\begin{array}{l}1.2776 \\
1.1021 \\
0.9084 \\
0.6978 \\
0.4756 \\
0.2489\end{array}$ & $\begin{array}{l}0.6857 \\
0.9916 \\
1.3027 \\
1.6198 \\
1.9440 \\
2.2755\end{array}$ & $\begin{array}{l}0.0938 \\
0.3811 \\
0.6970 \\
1.0419 \\
1.4123 \\
1.8022\end{array}$ \\
\hline
\end{tabular}


Table I Numerical Results (Cont'd)

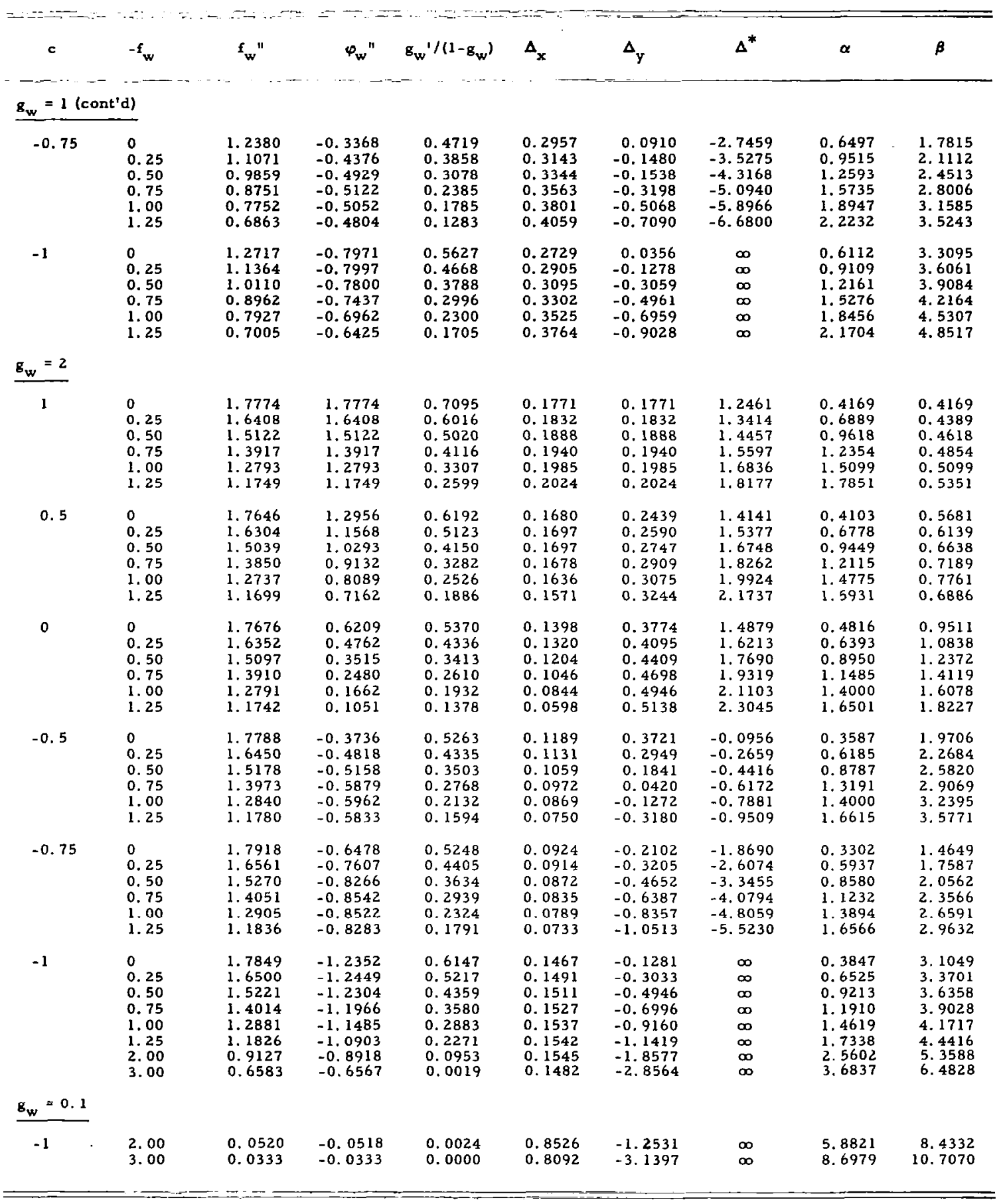




\section{References}

1. Eckert, E. R. G., "Heat transfer and temperature profiles in laminar boundary layers on a sweat-cooled wall, " AAF Tech. Rept. 5646, Air Materiel Command (November 1947).

2. Morduchow, M., "On heat transfer over a sweat-cooled surface in laminar compressible flow with a pressure gradient," J. Aeronaut. Sci. 19, 705-711 (1952).

3. Reshotko, E. and Cohen, C. B., "Heat transfer at the forward stagnation point of blunt bodies," NACA TN 3513 (1955).

4. Scala, S. M., "The injection of air into the dissociated hypersonic laminar boundary layer," Readers' Forum, J. Aero/Space Sci. 25, $461-462$ (1958).

5. Howe, J. T. and Mersman, W. A., "Solutions of the laminar compressible boundary-layer equations with transpiration which are applicable to the stagnation regions of axisymmetric blunt bodies," NASA TN D-12 (1959).

6. Chung, P. M., "Shielding stagnation surfaces of finite catalytic activity by air injection in hypersonic flight," NASA TN D-27 (1959).

7. Hayday, A. A., "Mass transfer cooling in a laminar boundary layer in steady two-dimensional stagnation flow, "University of Minnesota Technical Note 19, AFOSR TN 58337, AD 154241 (1958).

8. Hoshizaki, H. and Smith, H. J., "The effect of helium injection at an axially symmetric stagnation point," Readers' Forum, J. Aero/ Space Sci. 26, 399-400 (1959).

9. Libby, P. A., "The homogeneous boundary layer at an axisymmetric stagnation point with large rates of injection, "J. Aeronaut. Sci. 29, $48-60(1962)$.

10. Howarth, L., "The boundary layer in three dimensional flow. Part II. The flow near a stagnation point," Phil. Mag. 42, 335, 1433-1440 (1951).

11. Reshotko, E., "Heat transfer to a general three-dimensional stagnation point," Jet Propulsion 28, 58-60 (1958).

12. Davey, A., "Boundary-layer flow at a saddle point of attachment," J. Fluid Mech. 10, 593-610 (1961).

13. Poots, G., "Compressible laminar boundary-layer flow at a point of attachment," J. Fluid Mech. 22, 197-208 (1965). 


\section{References (Cont' $d$ )}

14. Bellman, R. "New directions of research in the theory of differential equations," Nonlinear Differential Equations and Nonlinear Mechanics, edited by J. P. LaSalle and S. Lipschitz (Academic Press, New York, 1963).

15. Kalaba, R., "Some aspects of quasilinearization," Nonlinear Differential Equations and Nonlinear Mechanics, edited by J. P. LaSalle and S. Lipschitz (Academic Press, New York, 1963).

16. Radbill, J. R., "Application of quasilinearization to boundary-layer equations," AIAA J. 2, $1860-1862$ (1964).

17. Libby, P. A. and Chen, K., "Remarks on quasilinearization applied to boundary layer calculations (accepted by the AIAA J.).

18. Cohen, C. B. and Reshotko, E., "Similar solutions for compressible laminar boundary layer with heat transfer and pressure gradient," NACA TR 1293 (1956).

19. Fox, H. and Libby, P. A., "Helium injection into the boundary layer at an axisymmetric stagnation point," J. Aeronaut. Sci. 29, 921-935 (1962).

20. Zeiberg, S. L., "Similar laminar boundary layer with large injection," AIAA J. 4, 157-158 (1966).

21. Moore, F. K., "Three-dimensional boundary layer theory," Advances in Applied Mechanics (Academic Press, Inc., New York, 1956), Vol. IV, pp. 160-224.

22. Lighthill, M. J., "On displacement thickness," J. Fluid Mech. 4, 383-392 (1958).

23. Mann, W. M. Jr., "Effective displacement thickness for boundary layers with surface mass transfer," AIAA J. 1, 1181-1182 (1963).

24. Hayashi, N., "Displacement thickness of the boundary layer with blowing, " ALAA J. 3, 2348-2349 (1965). 

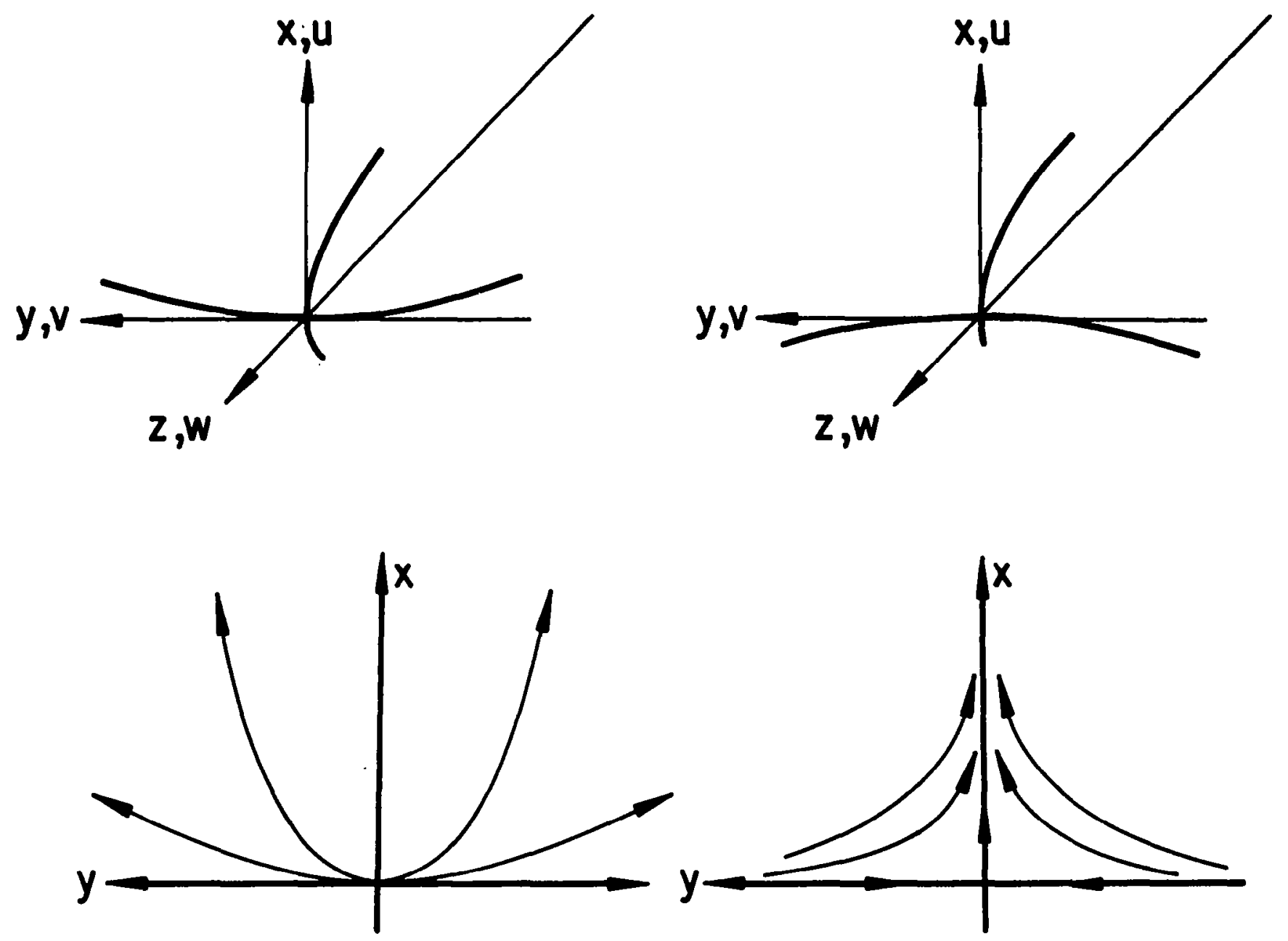

a) NODAL POINT

b) SADDLE POINT

$$
0 \leq \mathrm{C} \leq 1
$$

$-1 \leq \mathrm{C} \leq \mathrm{O}$

Figure 1.- Schematic representation of coordinates, velocity components, and streamlines in the external stream. 


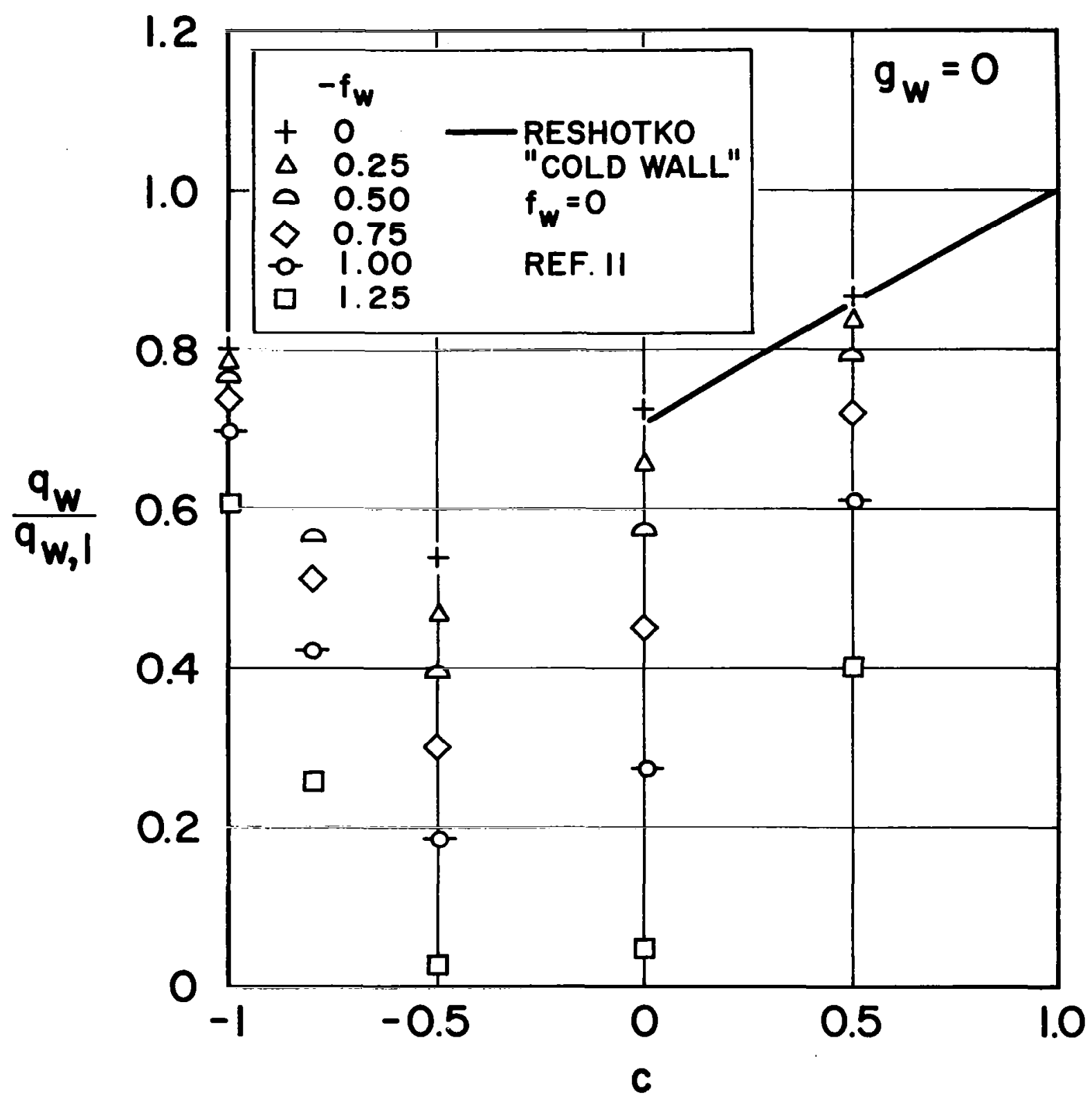

Figure 2.- The influence of the ratio of velocity gradient in heat transfer with mass transfer: cold wall case, $g_{w}=0$. 


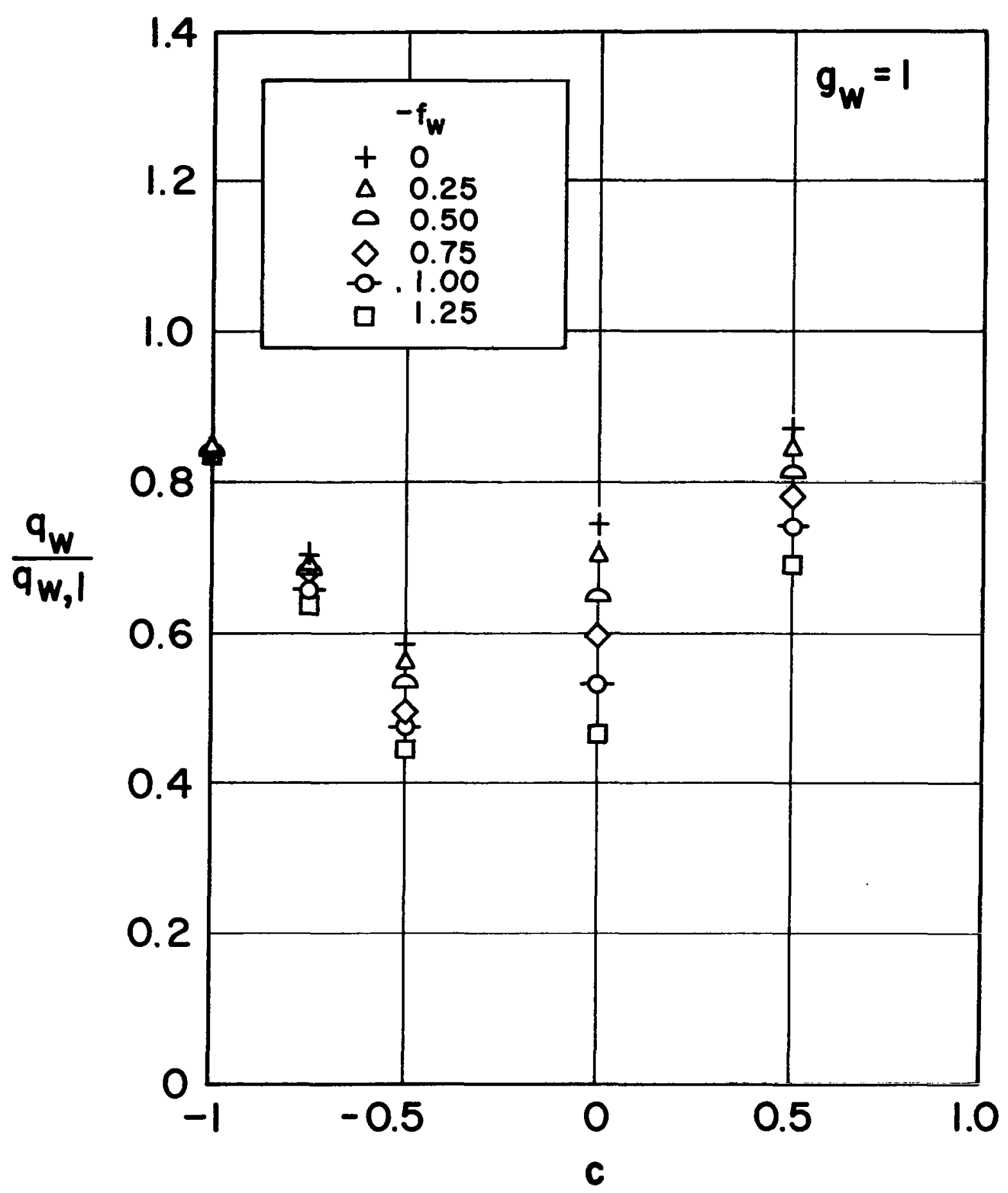

Figure 3.- The influence of the ratio of velocity gradient in heat transfer with mass transfer: incompressible case, $g_{w}=1$. 


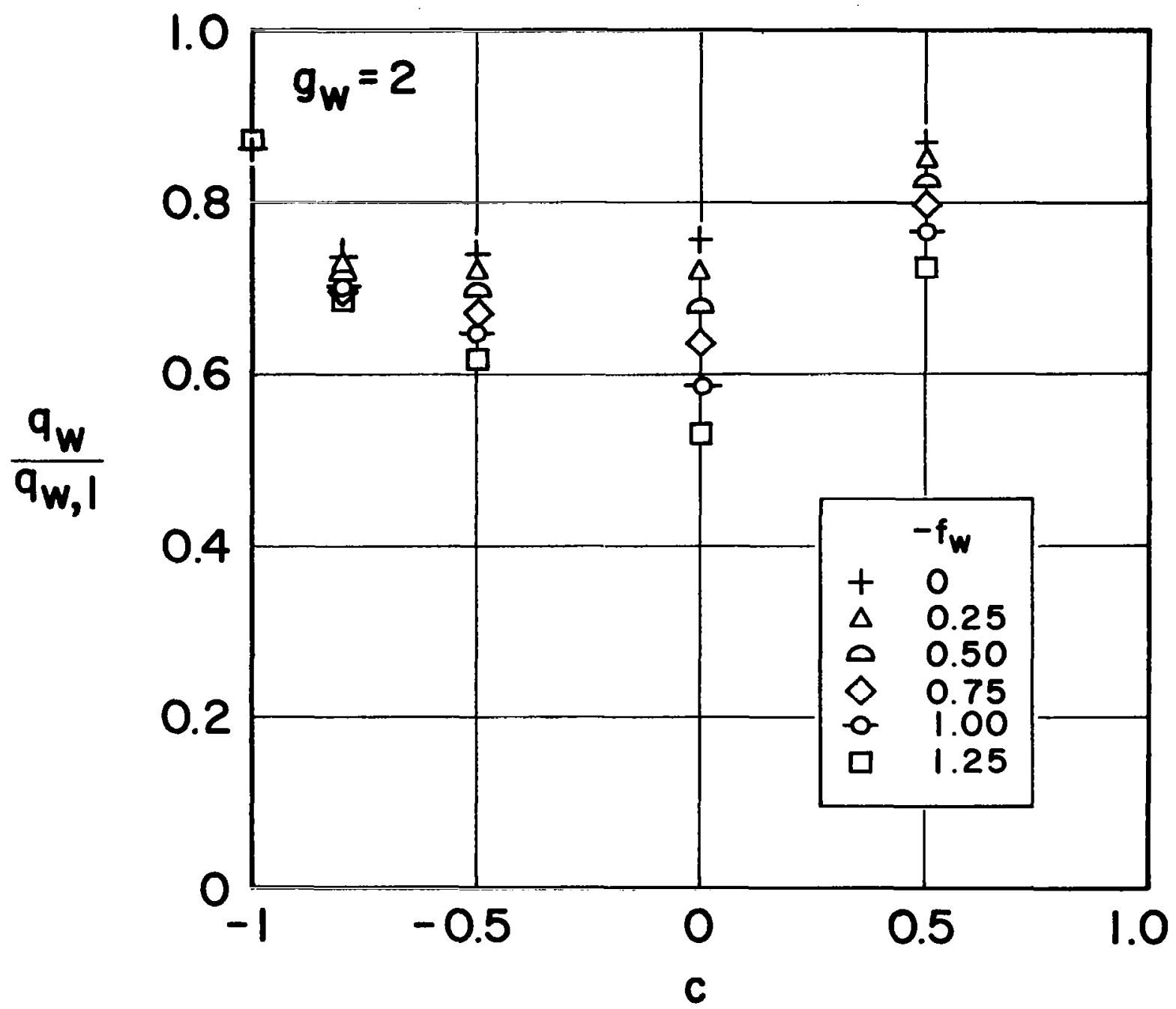

Figure 4.- The influence of the ratio of velocity gradient in heat transfer with mass transfer: heated wall case, $g_{w}=2$. 


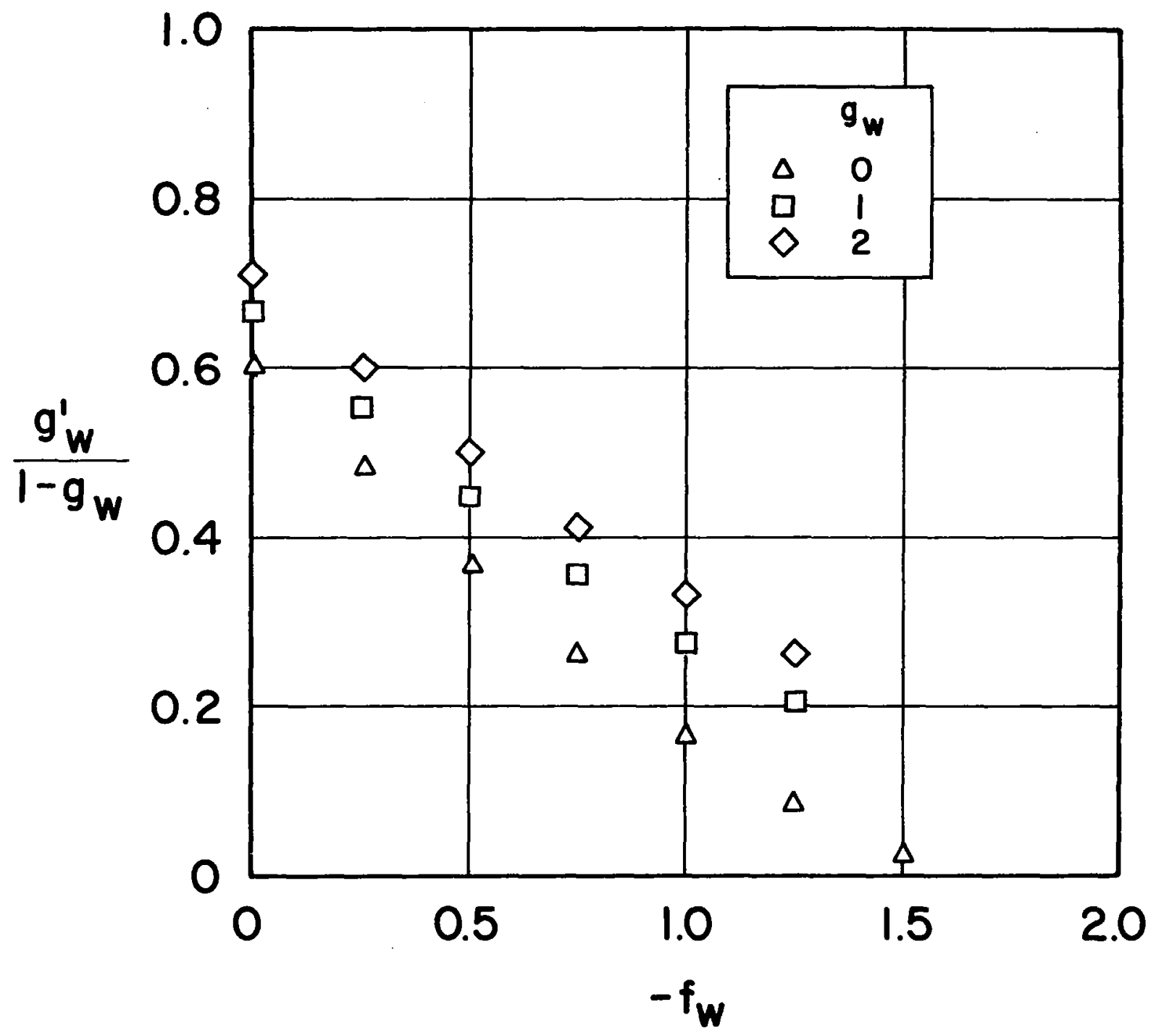

Figure 5.- Heat transfer parameter at an axisymmetric stagnation point, $c=1$. 


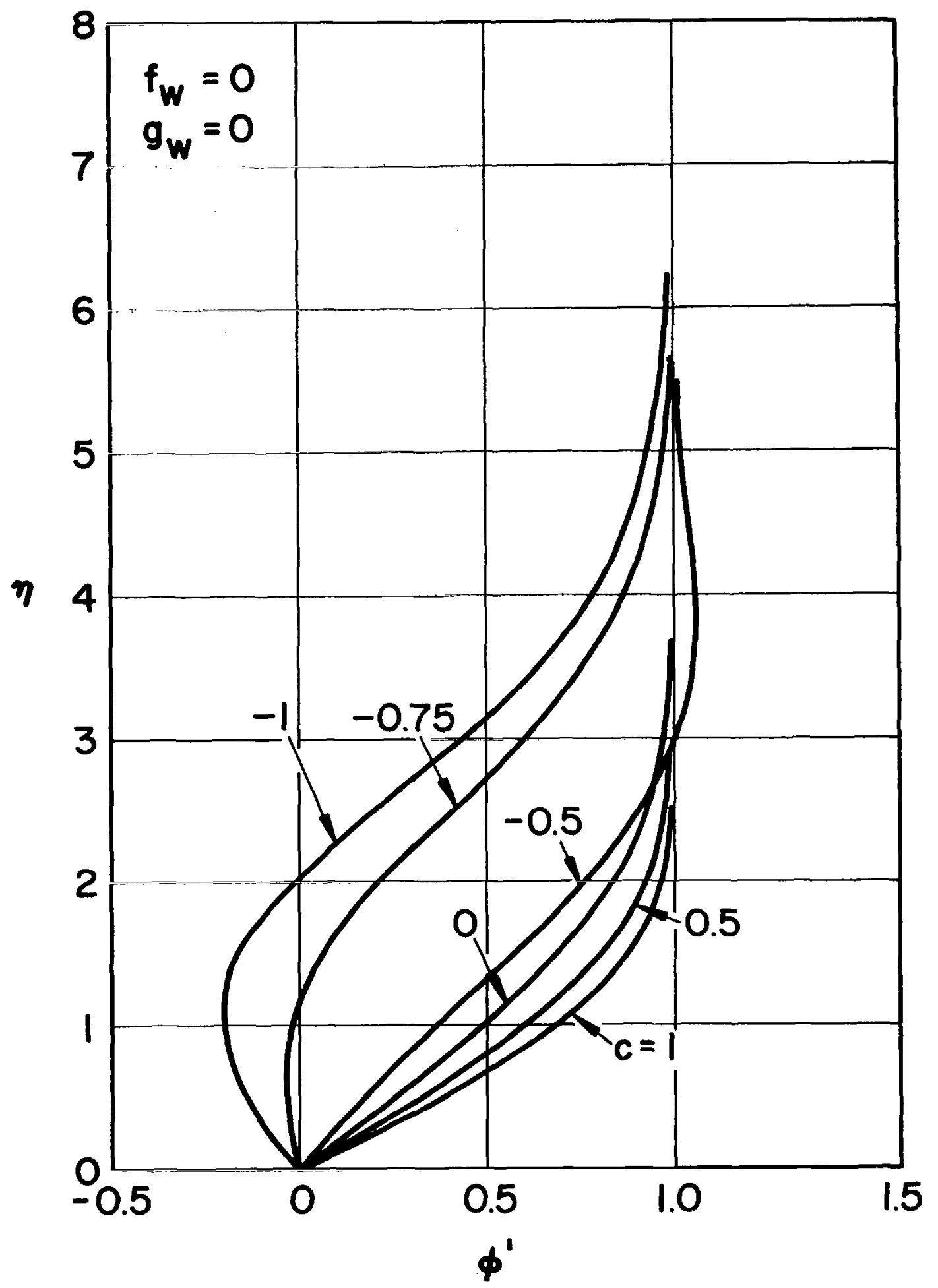

Figure 6.- The velocity profiles in the y-direction: cold wall, $f_{W}=0$, $\varepsilon_{W}=0$. 


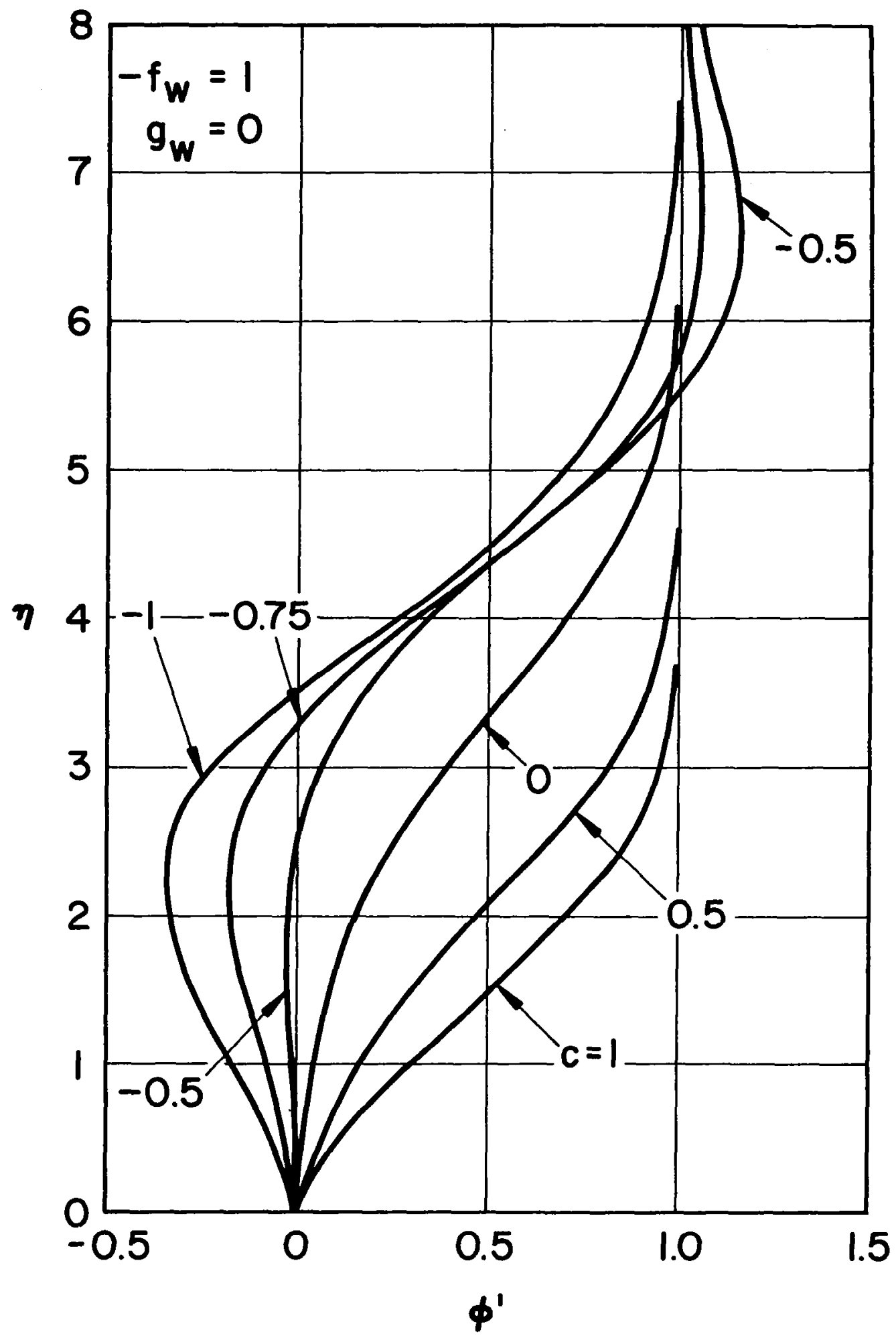

Figure 7.- The velocity profiles in the $y$-direction: cold wall, $-f_{\mathrm{W}}=1$, $g_{\mathrm{W}}=0$. 


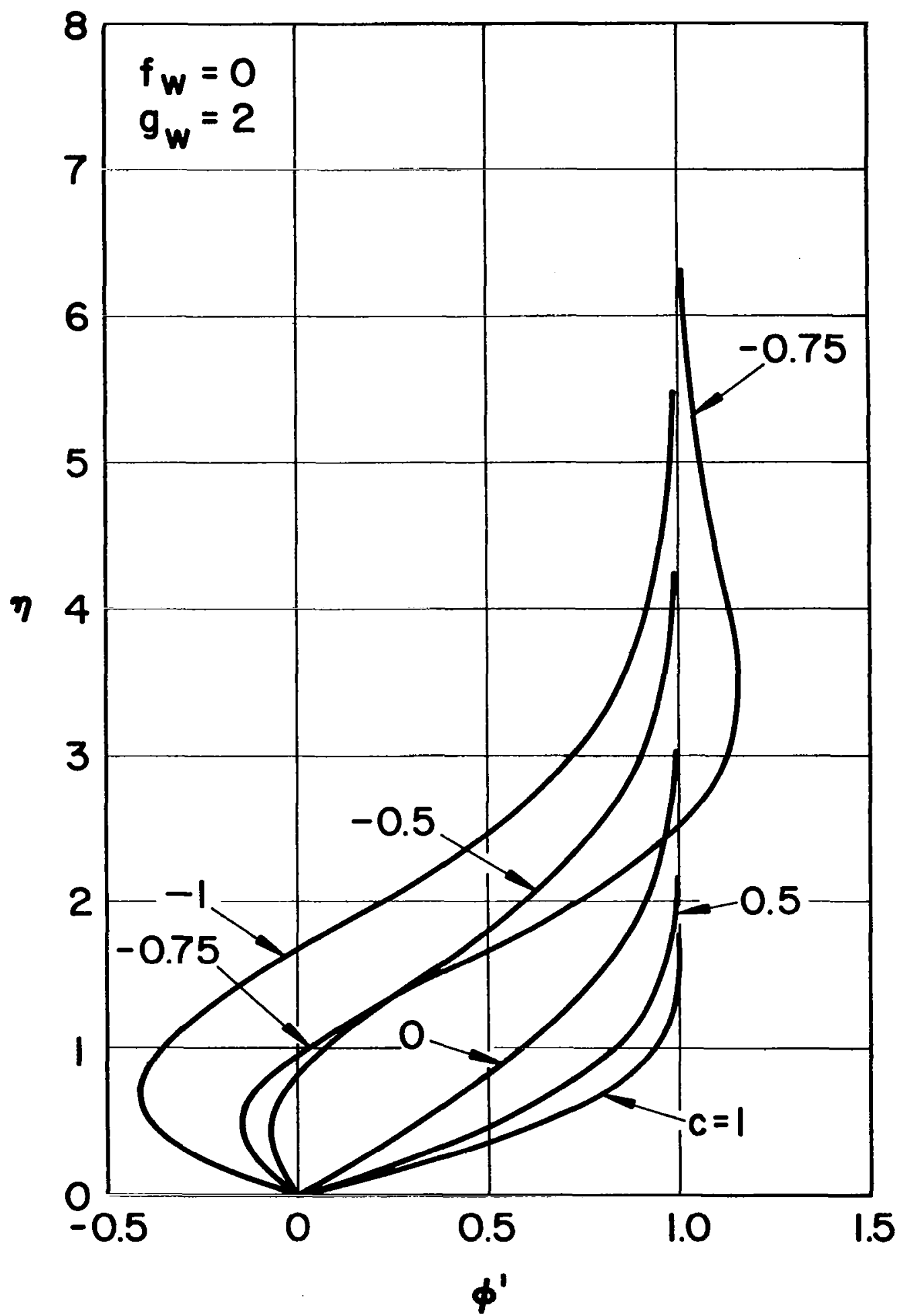

Figure 8. - The velncity profiles in the $y$-direction: heated wall, $f_{w}=0$, $g_{w}=2$. 


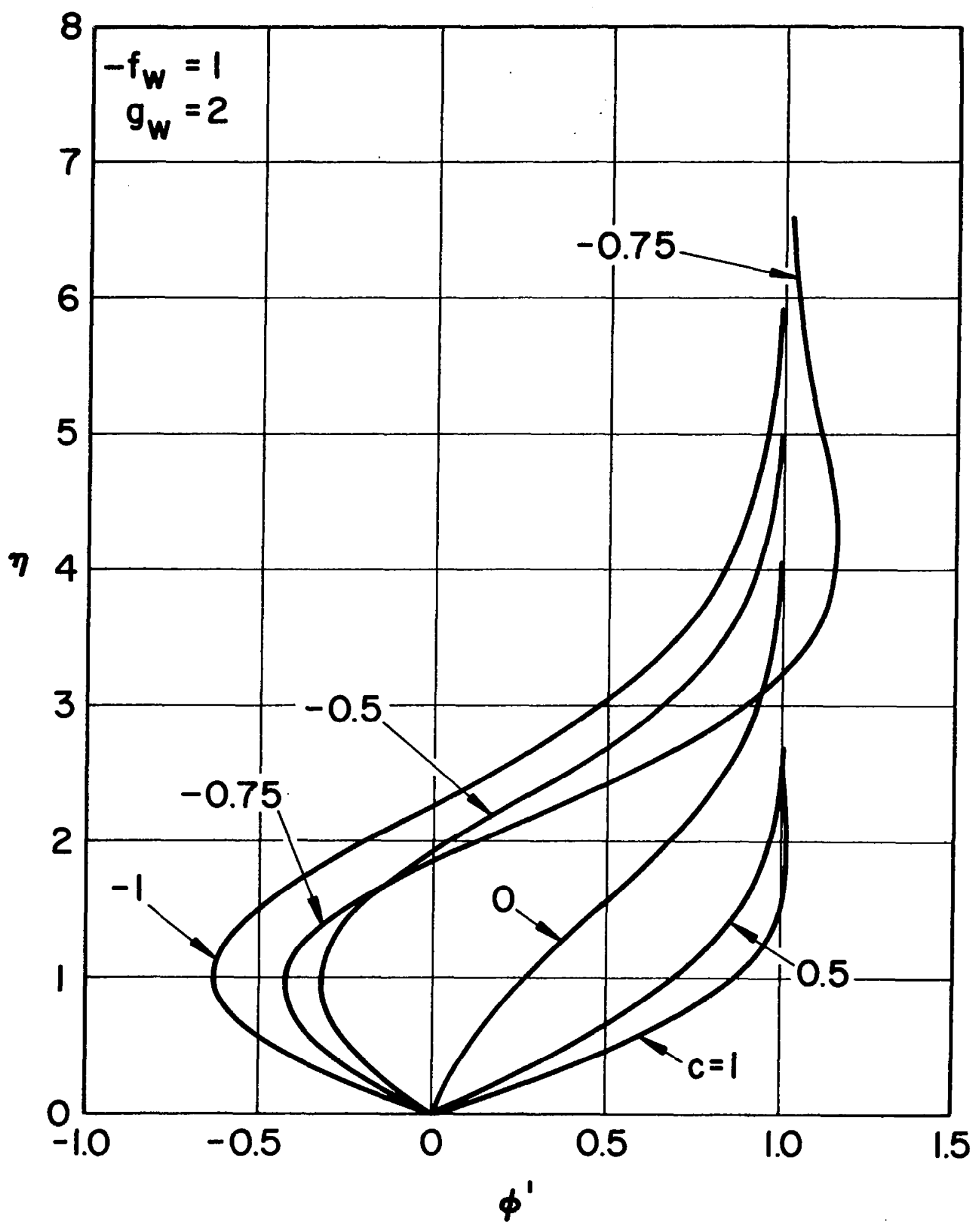

Figure 9.- The velocity profiles in the y-direction: heated wall, $-f_{\mathrm{w}}=1$, $\varepsilon_{w i}=2$. 


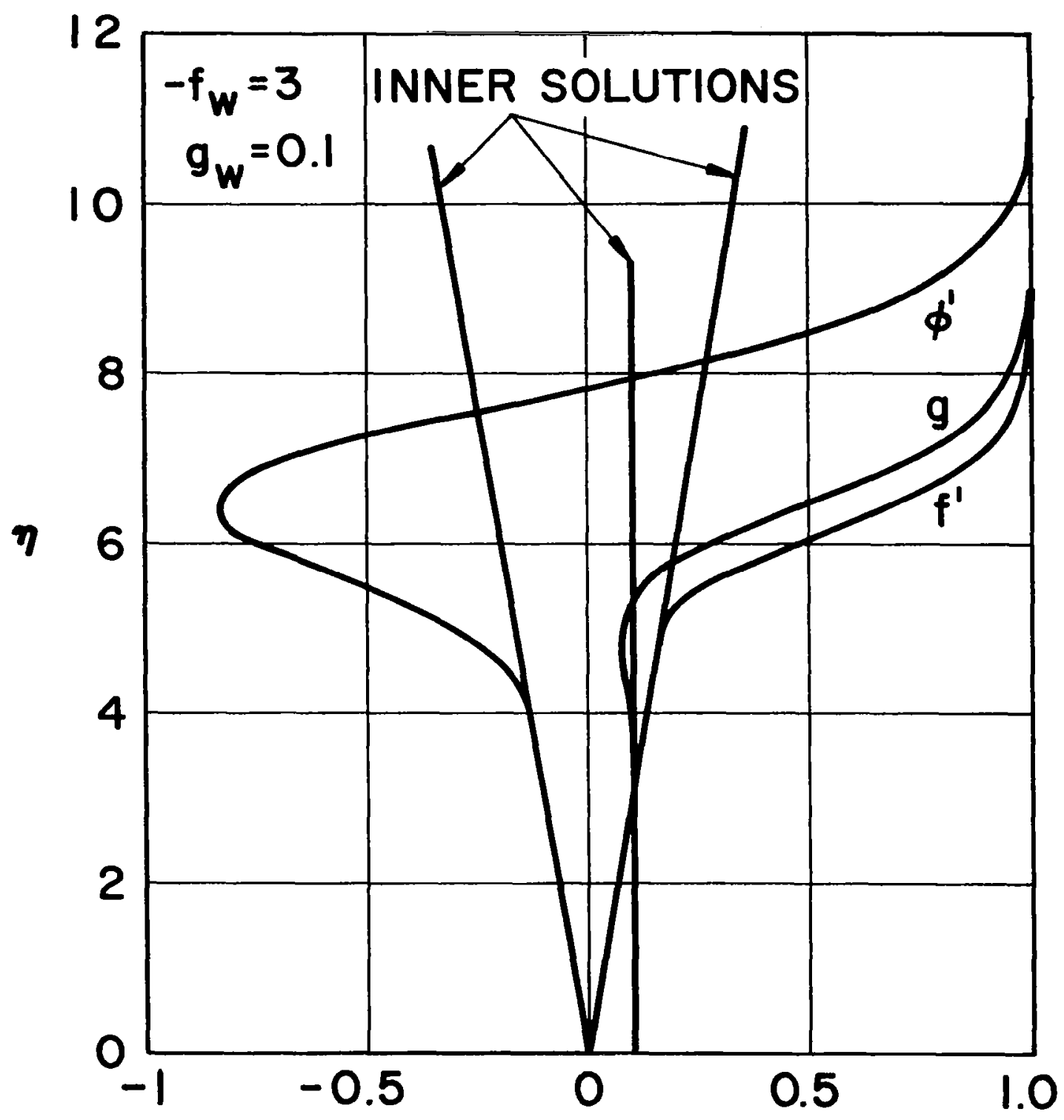

Figure 10.- The profiles for the saddle-point $c=-1$ with a large rate of injection: cold wall. 


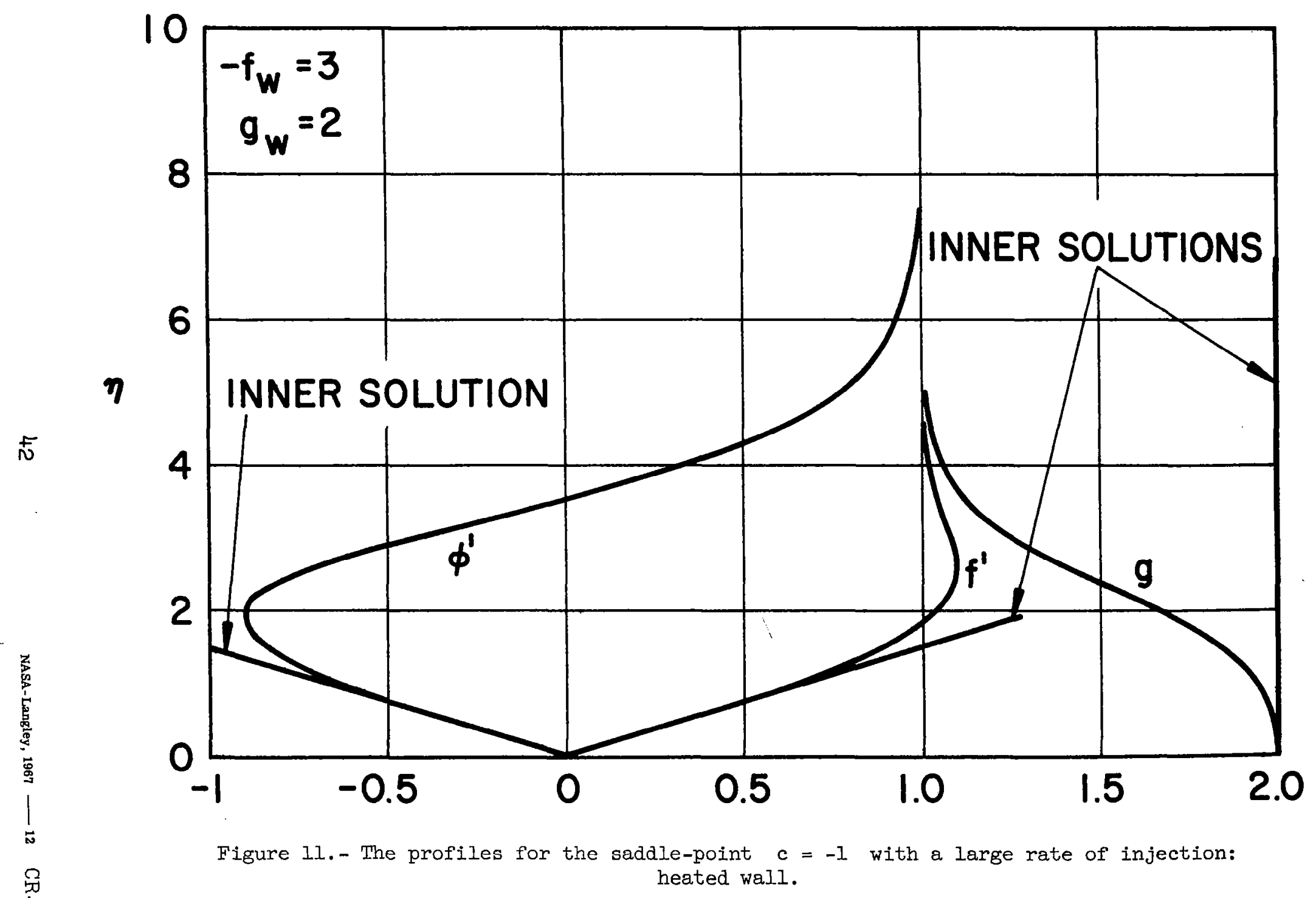

